\title{
مدى تضمين قيم المواطنة في منهاج التربية الوطنية و والمدنية للصف التاسع في الأردن (دراسة تطبيقية)
}

البريد الاكتروني: الأنتورة وجدان حسن محمود العزايزة

الملخص

لقد هدفت الدراسة الى معرفة درجة تضمين قيم المواطنة في منهاج التربية الوطنية والمدنية للصف التاسع في الأردن، وذلك في المجالات السياسية والاقتصادية والاجتماعية. لتحقيق غايات الدراسة، قامت الباحثة باعتماد النهج الوصفي التحليلي، وقامت الباحثة باستخدام استبيان، وقامت الباحثة باختيار عينة قصدية مكونة من 150 معلم ومعلمة من معلمي التربية الوطنية و المدنية للصف التاسع من 150 مدرسة حكومية في عمان، الاردن، وتم ارسال الاستبيان الى افراد العينة عبر البريد الالكتروني، ونم استرداد 135 استمارة صالحة للتحليل، وبلغت نسبة الاسترداد 90\%، وتم استخدام اساليب التحليل الوصفية، ونم استخدام برنامج SPSS لتحليل البيانات ولقد تبين ان درجة تضمين قيم المواطنة في منهاج التربية الوطنية والمدنية للصف التاسع في الأردن تعد مرتفعة، وذللك في جميع المجالات مجتمعة ومنفصلة، واوصت الباحثة بتنظيم رحلات مدرسية في الاردن لأماكن تاريخية تسهم في تعزيز قيم المو اطنة وتعريف الطلبة بناريخ الأردن. 


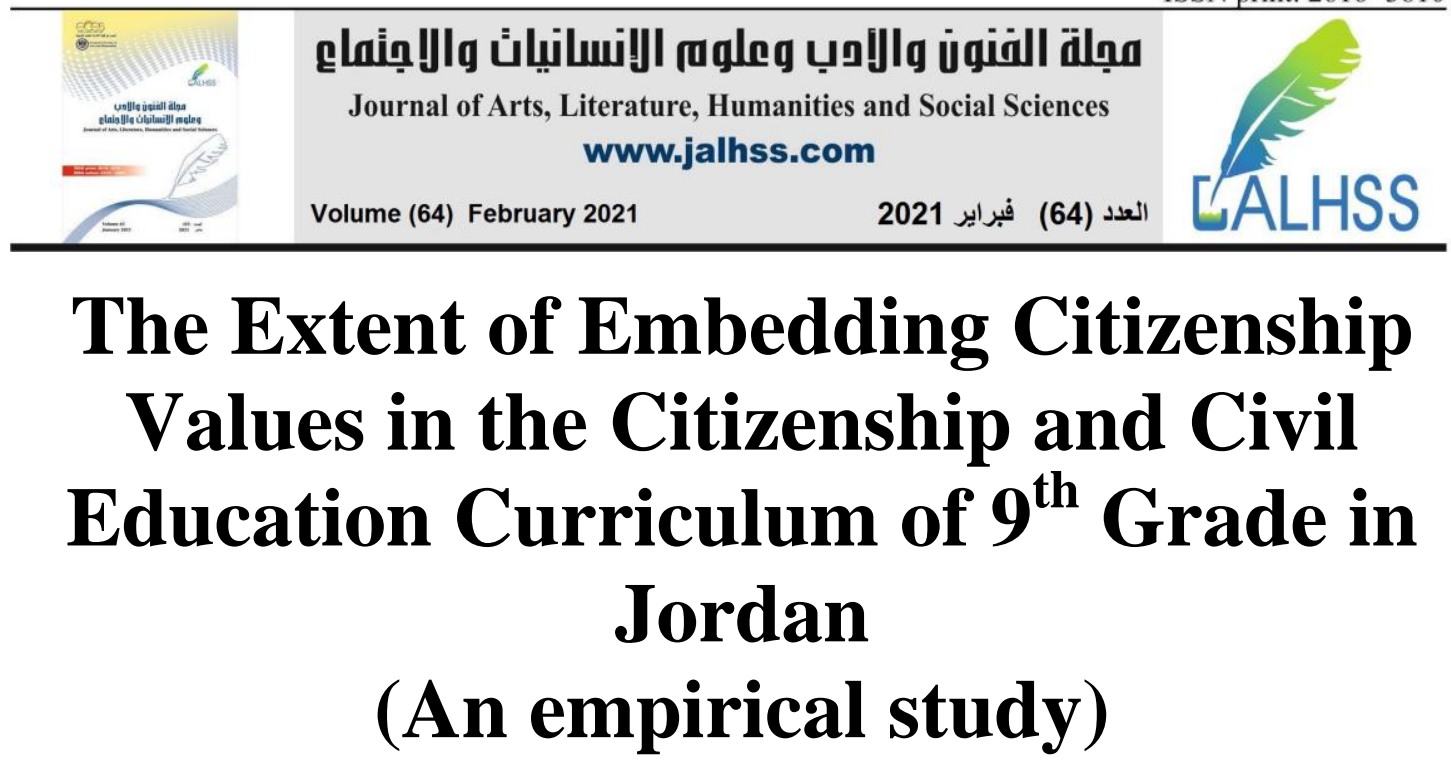

\author{
Dr. Wijdan Hassan Mahmoud Al-Azayzeh \\ Jordan \\ Email: wejdan963@yahoo.com
}

\begin{abstract}
The present study aimed to explore extent of embedding citizenship values in the citizenship and civil education curriculum of $9^{\text {th }}$ grade in Jordan. It aimed to explore that in the (political, economic and social areas). To meet the study's goals, the researcher adopted a descriptive analytical approach. She selected a purposive sample consisting from 150 female and male teachers who teach the course titled (citizenship and civil education) for $9^{\text {th }}$ grade. She selected those teachers from 150 public schools in Amman, Jordan. She sent the questionnaire forms to those teachers through email. 135 questionnaire forms were retrieved and considered valid for analysis. The response rate is $90 \%$. The SPSS software was used. The researcher found that the extent of embedding citizenship values in the citizenship and civil education curriculum of $9^{\text {th }}$ grade in Jordan is high in all the areas jointly and separately. She recommends organizing school trips for sites of historical value in Jordan. Such trips shall promote citizenship values and expand students' knowledge about the history of Jordan.
\end{abstract}

Keywords: citizenship, curriculum, citizenship and civil education, Jordan, empirical study. 


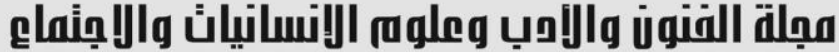

Journal of Arts, Literature, Humanities and Social Sciences

www.jalhss.com

ان العالم حاليا يواجه العديد من التحديات والتغيرات، كالعولمة و التطورات التكنولوجية واتلوات والاحداث السياسية

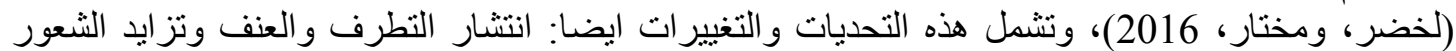

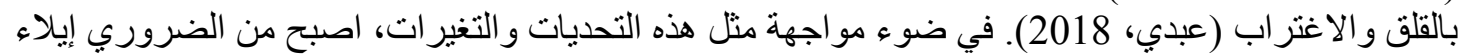

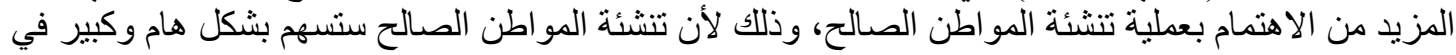

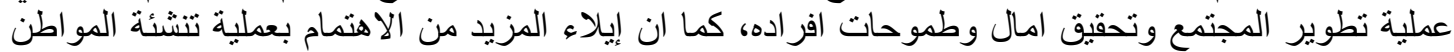

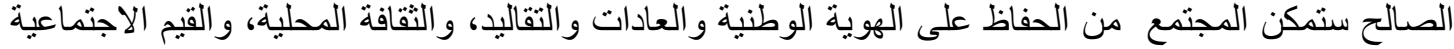

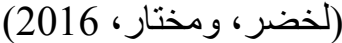
يمكن القيام بإيلاء الاهتمام بعملية تنشئة المواطن الصالح عبر إيلاء الاهتمام للتربية الوطنية في المدارس فئرس

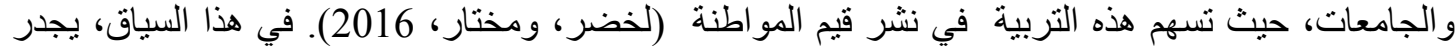

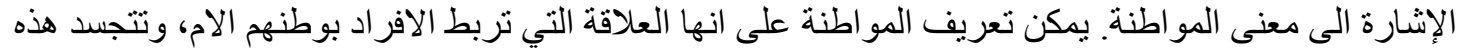

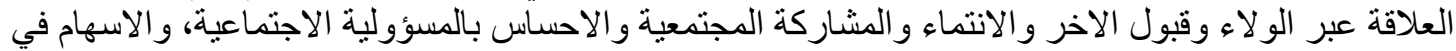

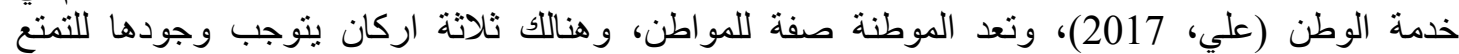

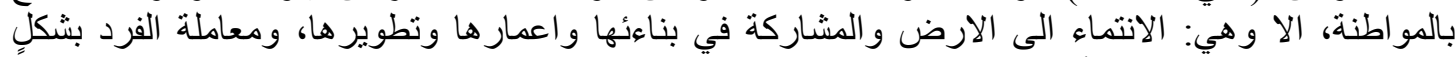

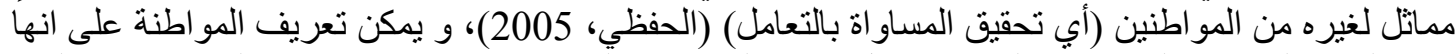

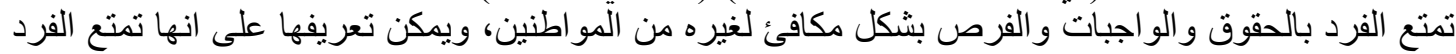

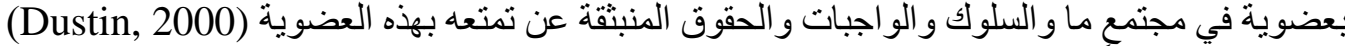

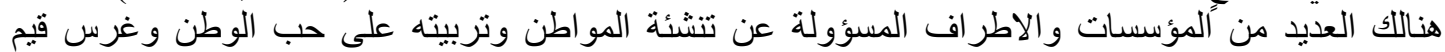

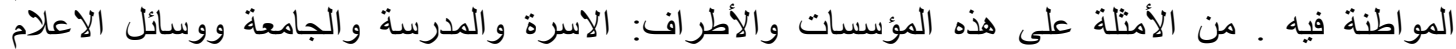

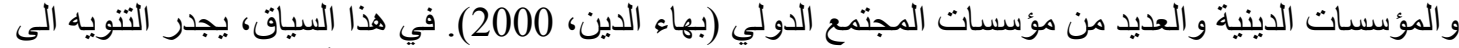

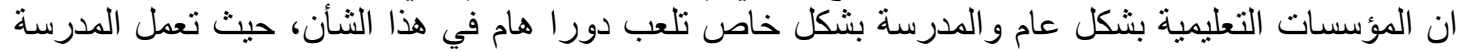

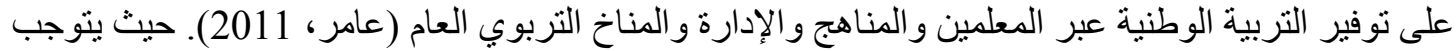

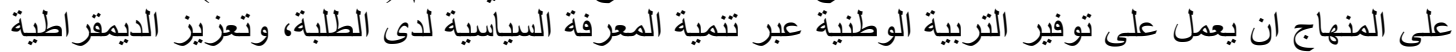

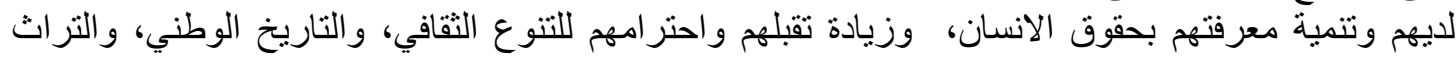

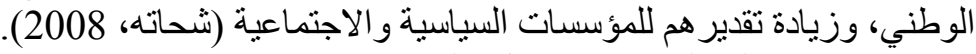

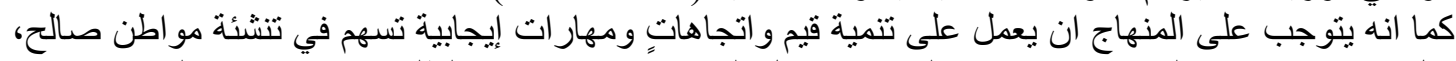

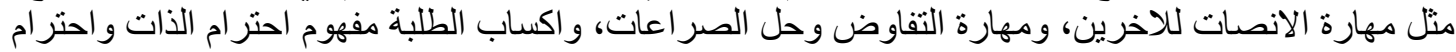

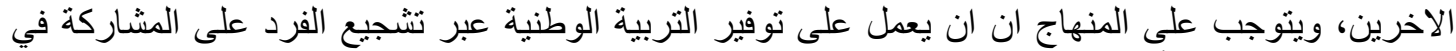

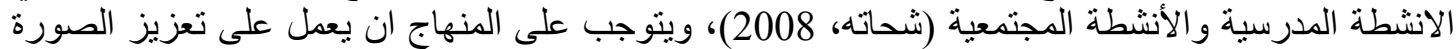

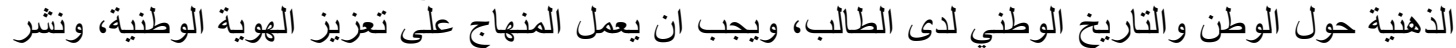

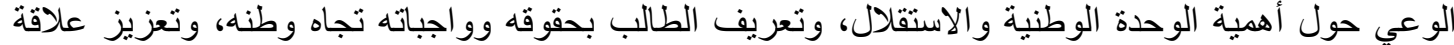

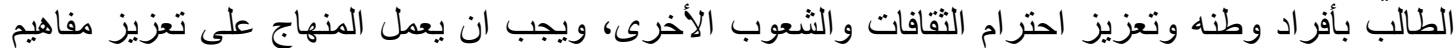

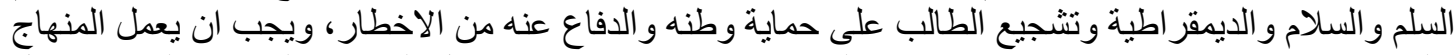

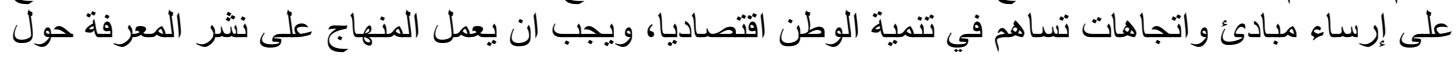

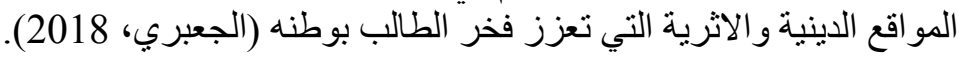

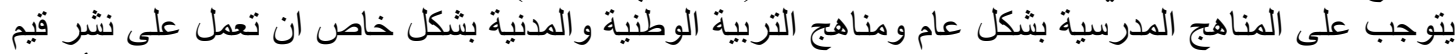

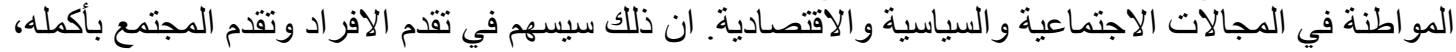

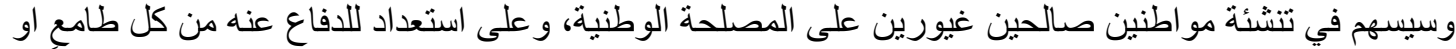

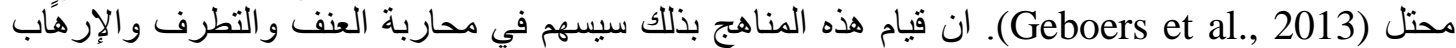

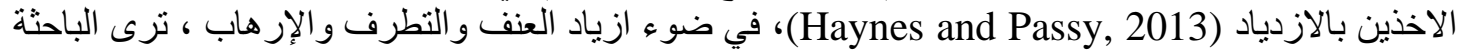

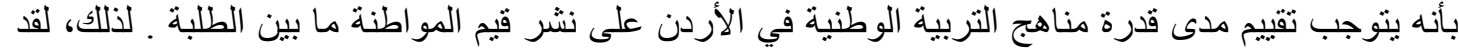

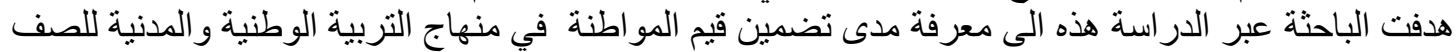
التاسع في الأردن من وجهة نظر معلمي هذه المادة. 


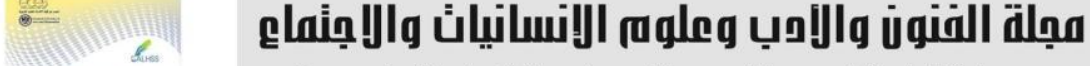 \\ Journal of Arts, Literature, Humanities and Social Sciences www.jalhss.com

تهدف الدراسة لمعرفة مدى تضمين قيم المواطنة في منهاج التربية الوطنية والمدنية للصف التاسع في الأردن من وجهة نظر معلمي هذه المادة

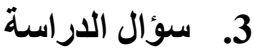

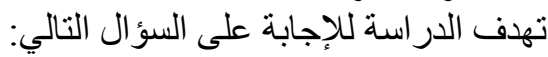

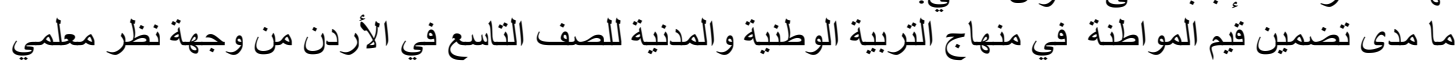

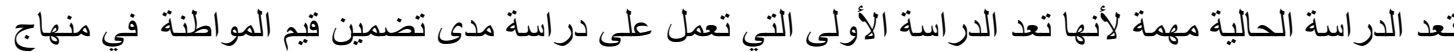

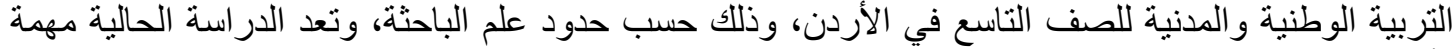

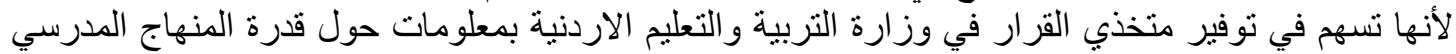

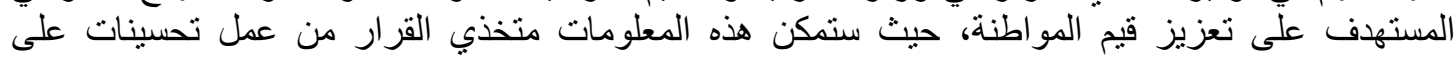

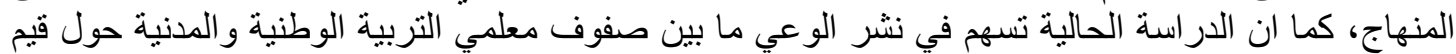

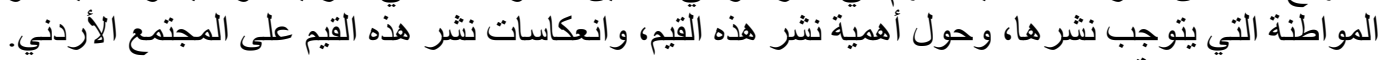

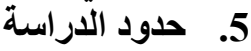

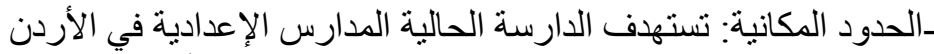

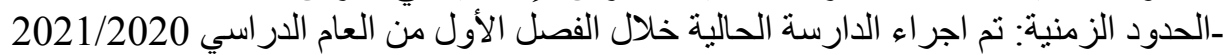

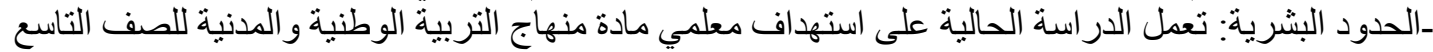

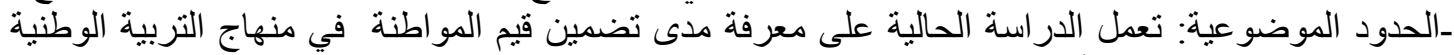

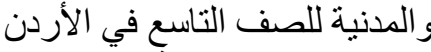

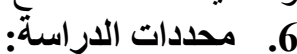
لا يمكن تعميم نتائج الدر اسة الحالية، وذللك لأن النتائج قد تختلف باختلاف المجتمع المستهدف وخصائص العينة

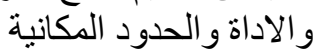

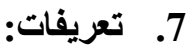

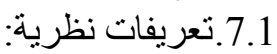

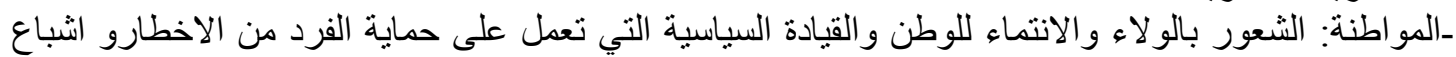

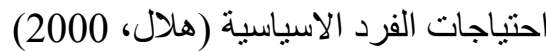

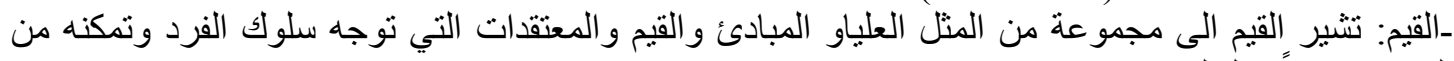

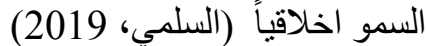

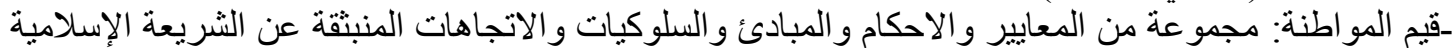

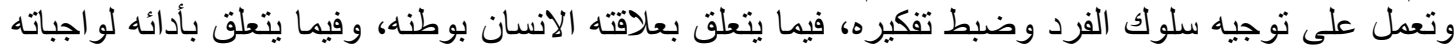

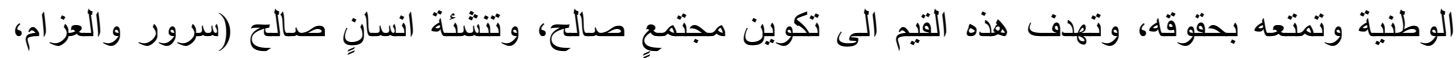

7. - 7.2 تعريفات إجر ائية:

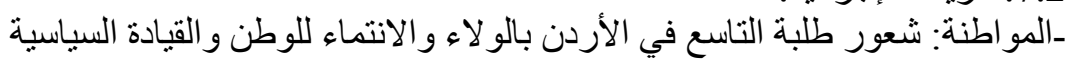

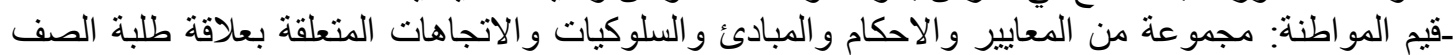

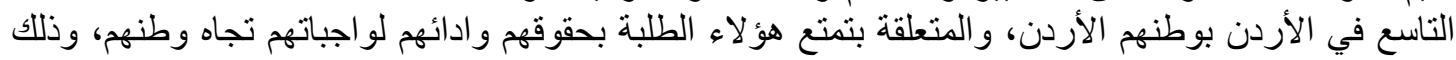

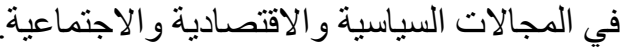

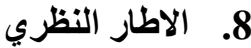

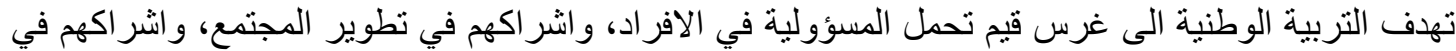

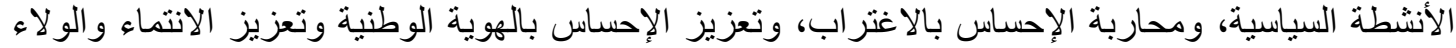

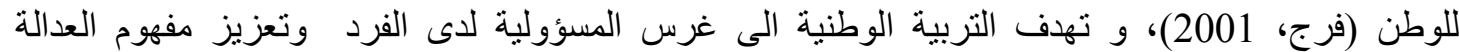

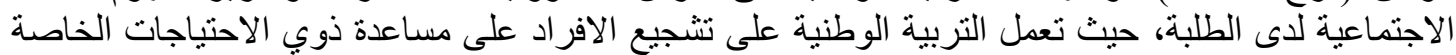




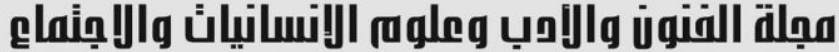

Journal of Arts, Literature, Humanities and Social Sciences www.jalhss.com

ومساعدة الفقراء، وتشجيع الفراد على القيام بواجباته تجاه وطنه (مثل دفع الضرائب)، وتشجيع الفرد على لمائ

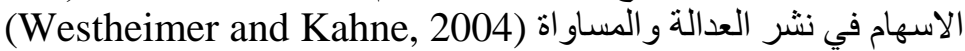

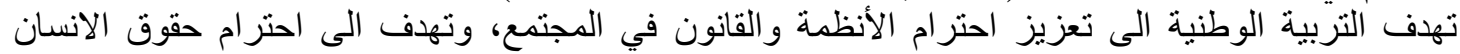

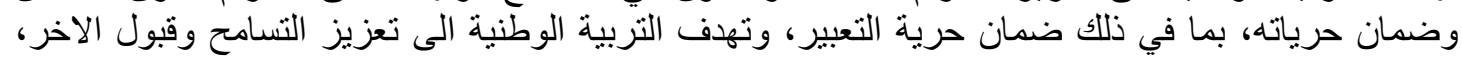

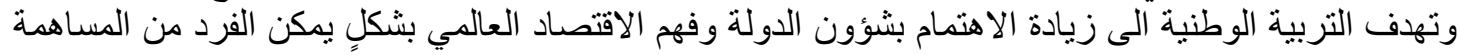

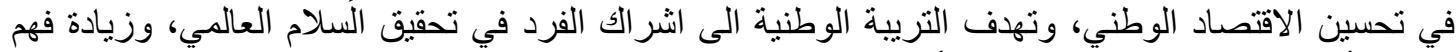

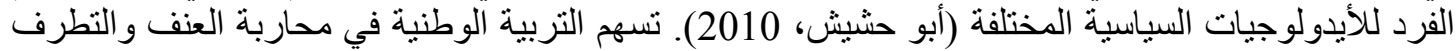

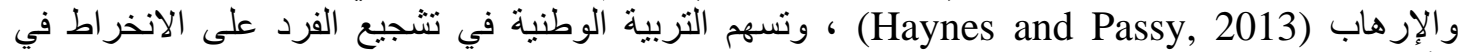

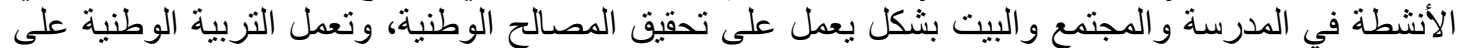

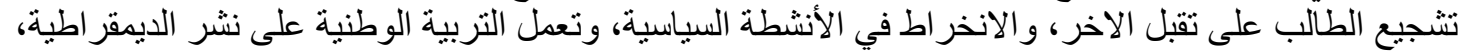

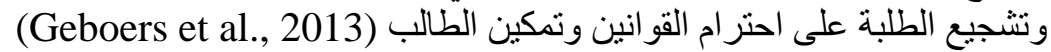

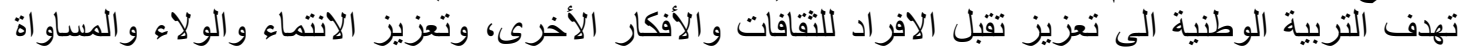

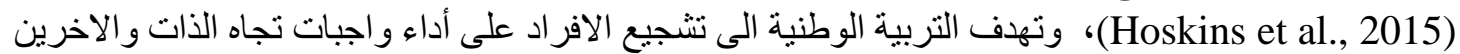

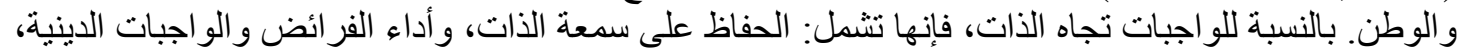

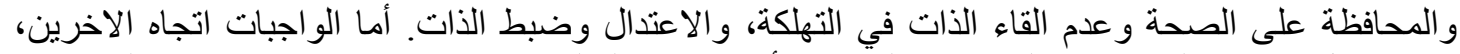

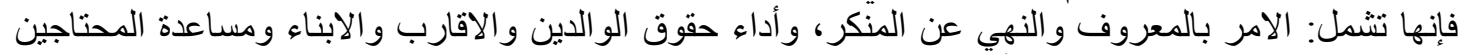

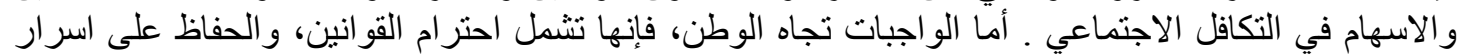

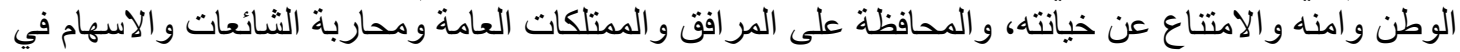

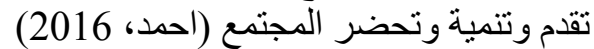

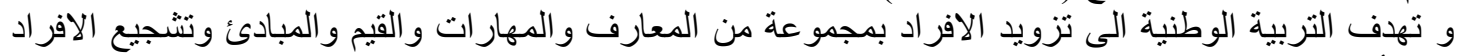

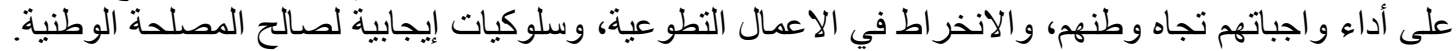

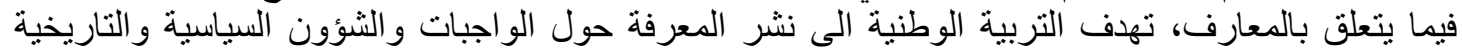

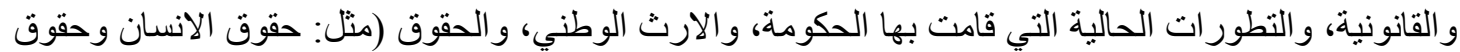
المر أة و الحقوق الدستورية، وحقوق الأطفال) و الحريات (Altintaş and Karaaslan, 2019)

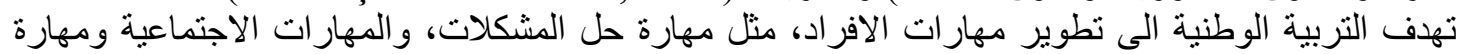

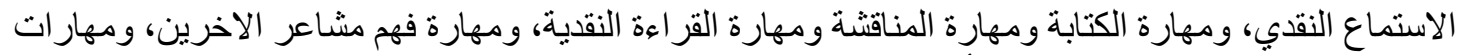

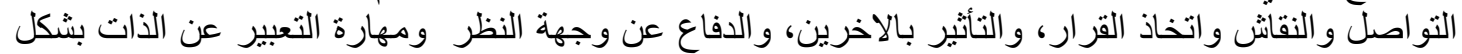

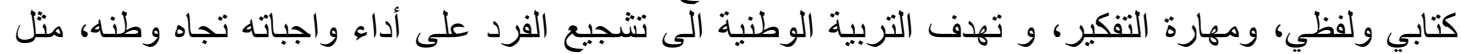

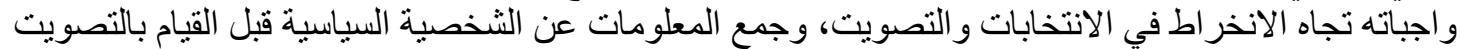

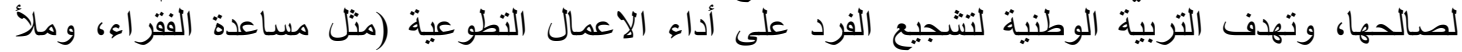

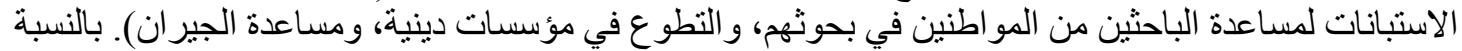

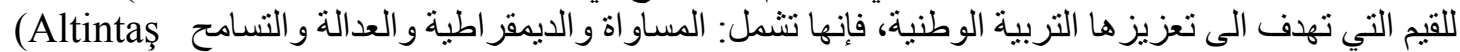
and Karaaslan, 2019)

9 . الاراسات التطبيقية باللغة الانجليزية:

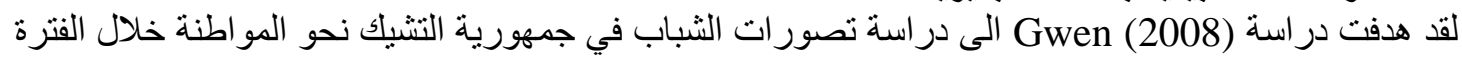

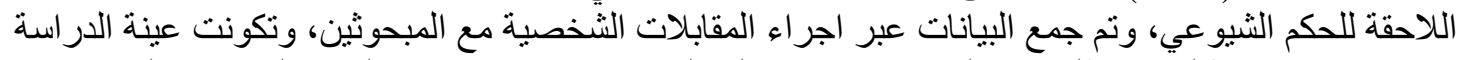

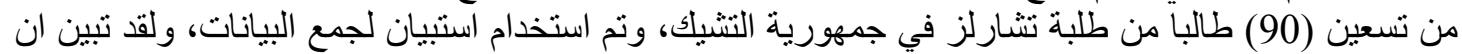

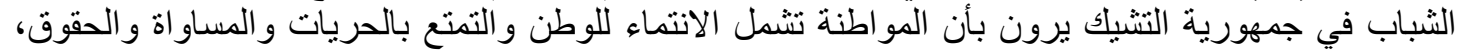

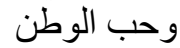
لقد هدفت دراسة (2008) Koutselini الى دراسة تصورات الطلبة الجامعيين الذين يمارسون مهنة التدريس

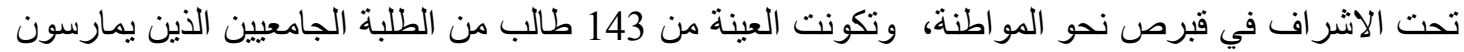

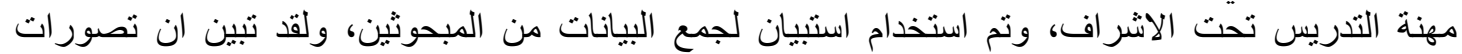

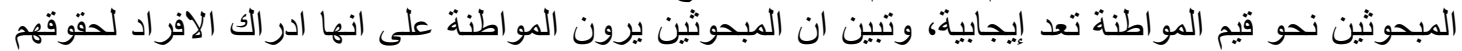

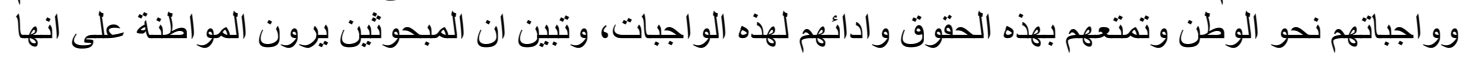




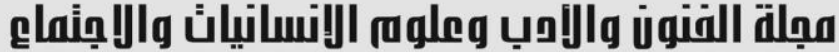

Journal of Arts, Literature, Humanities and Social Sciences

www.jalhss.com

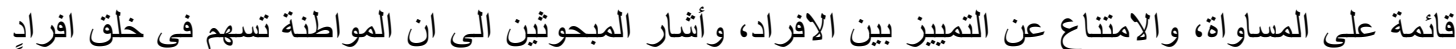

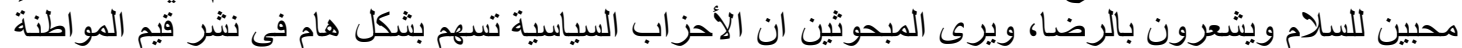

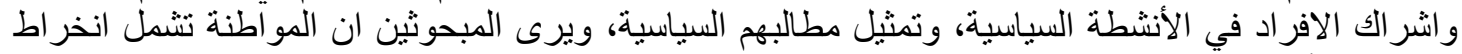

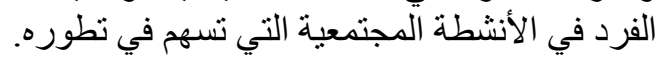

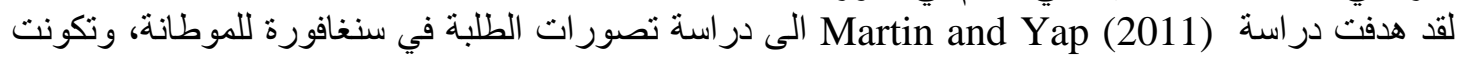

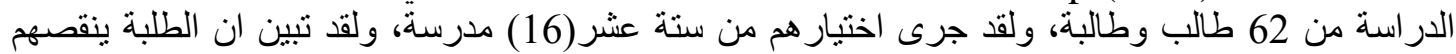

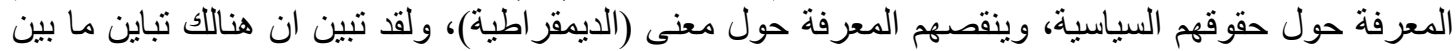

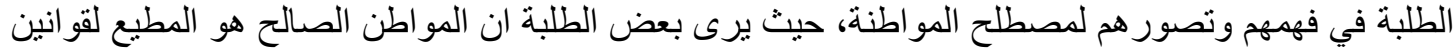

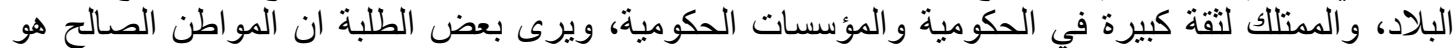

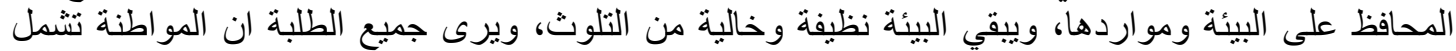
طاعة القو انين و المشاركة في التصويت

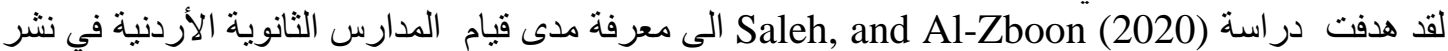

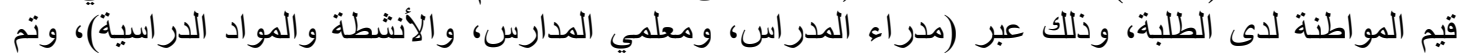

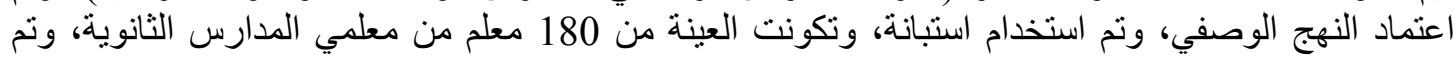

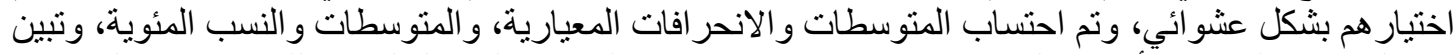

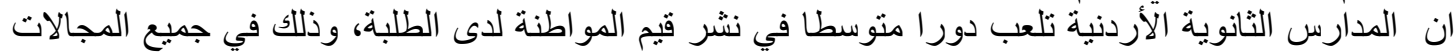

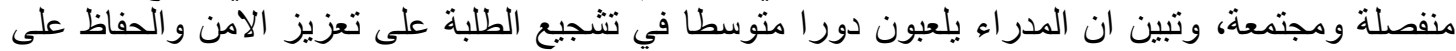

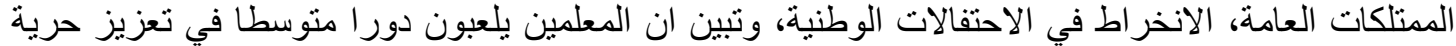

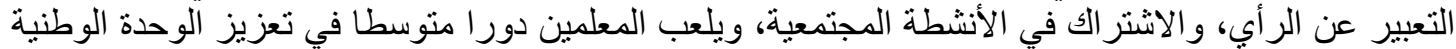

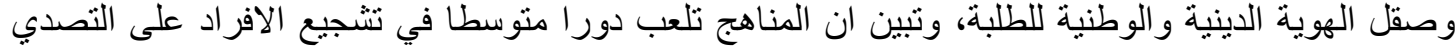

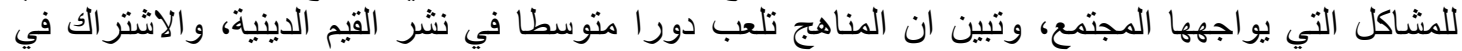

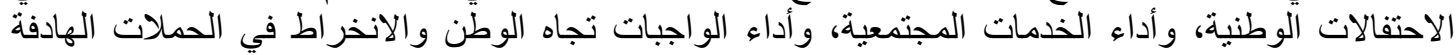

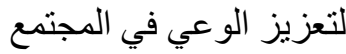

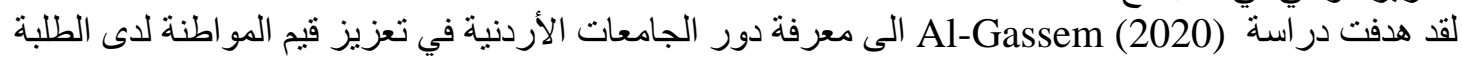

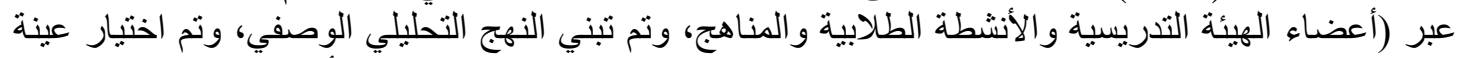

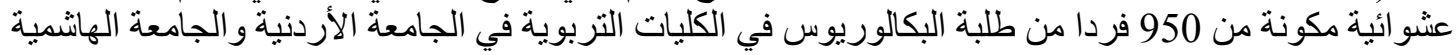

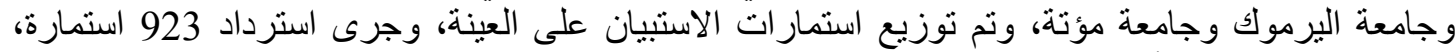

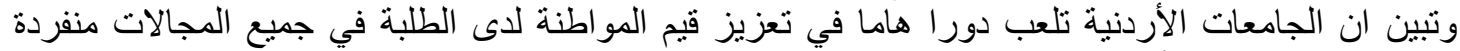

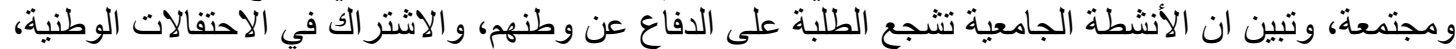

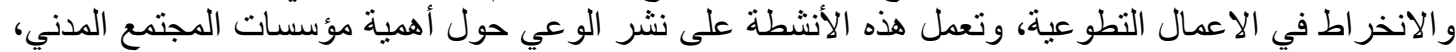
و احتر ام القو انين.

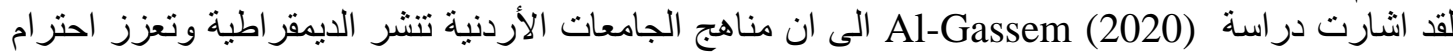

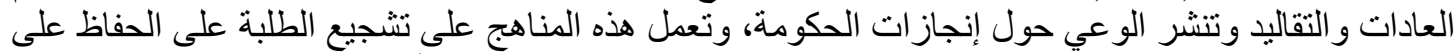

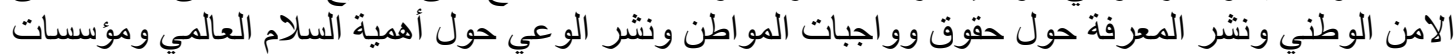

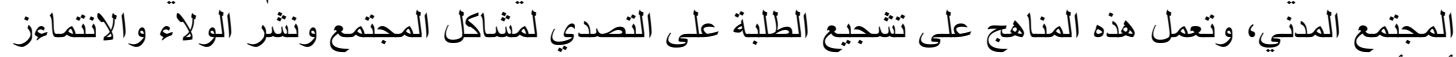

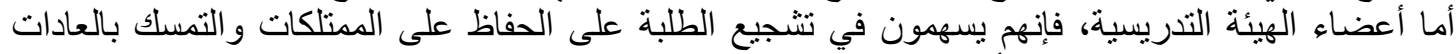

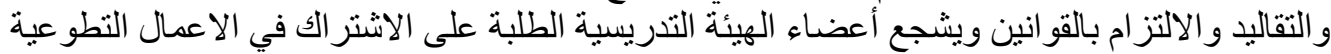

10. الدراسات التطبيقية باللغة العربية:

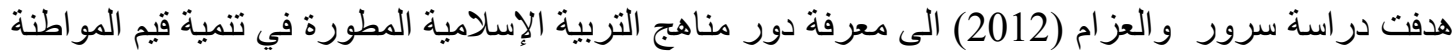

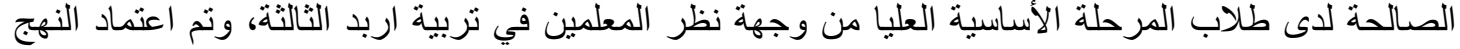

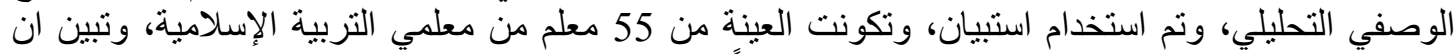

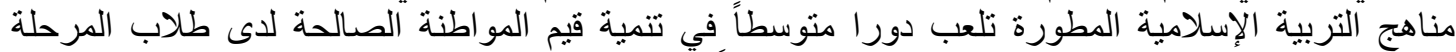
الأساسية العليا، وتبين ان هذه المناهج تلعب دور النبا منوسطاً في تعديل سلوك المو الطنة 


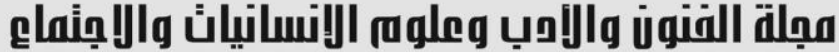

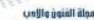

Journal of Arts, Literature, Humanities and Social Sciences

www.jalhss.com

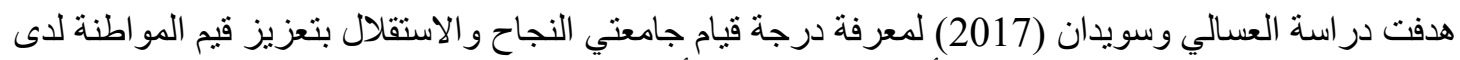

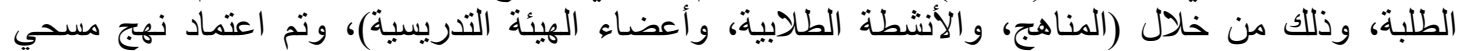

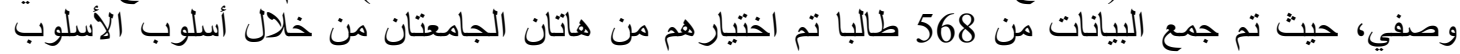

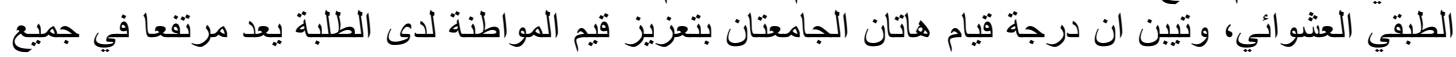

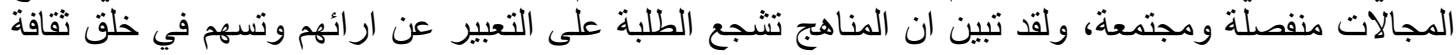

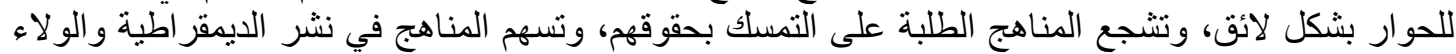

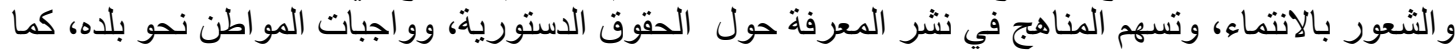

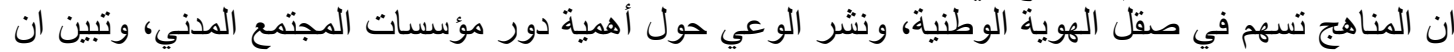

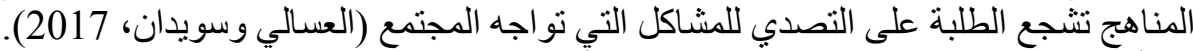

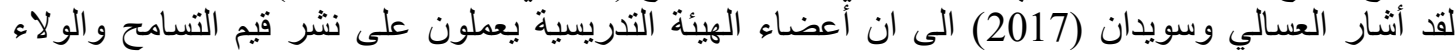

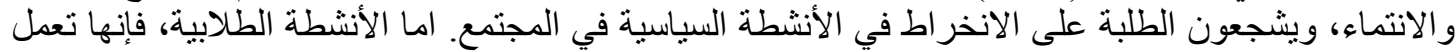

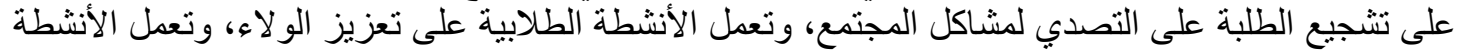

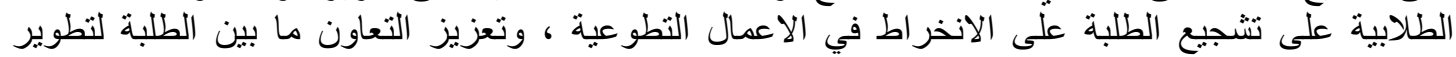

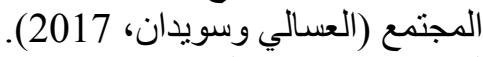

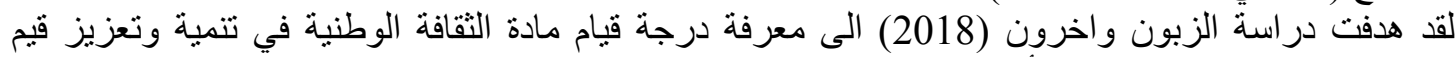

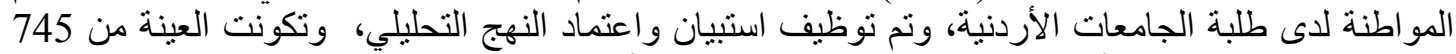

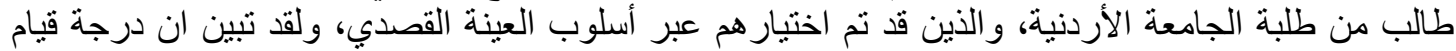

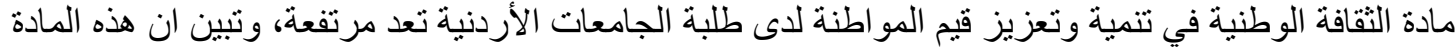

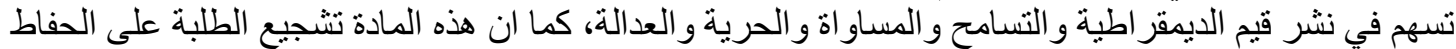

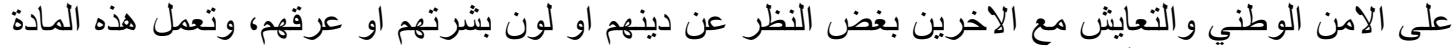

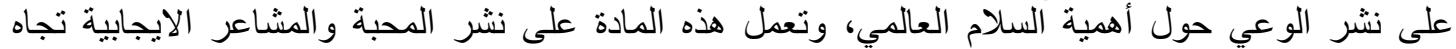

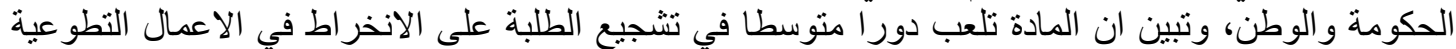
والاشتر الك في الاحتفالات الوطنية ان الونية

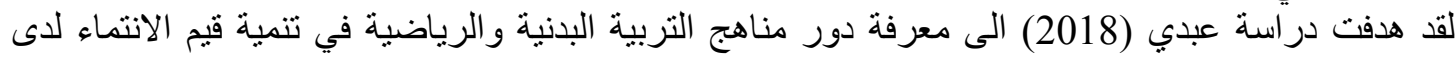

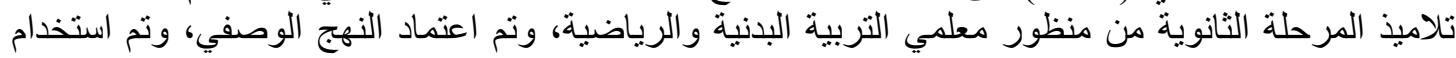

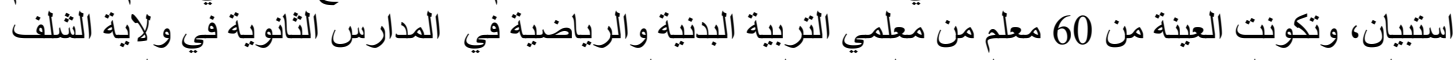

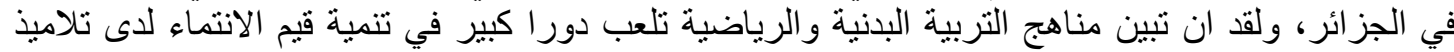

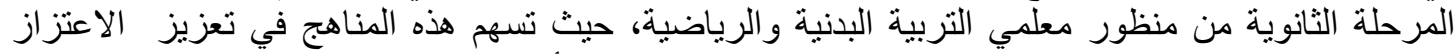

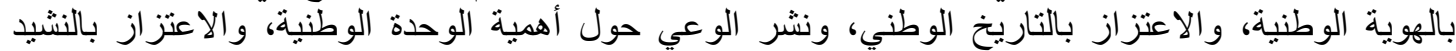

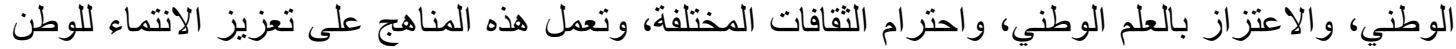

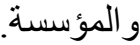

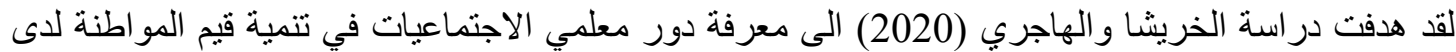

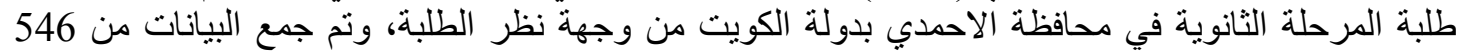

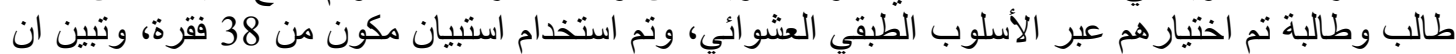

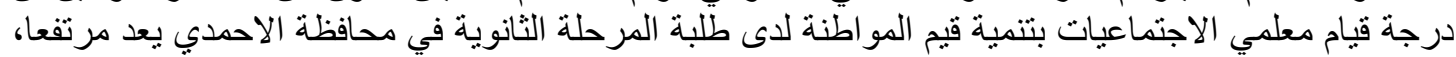

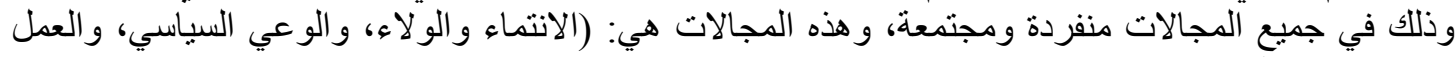

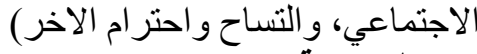

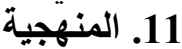

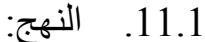
لقد عملت الباحثة على اتباع النهجي التحليلي الوصفي

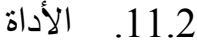

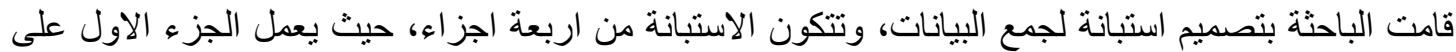

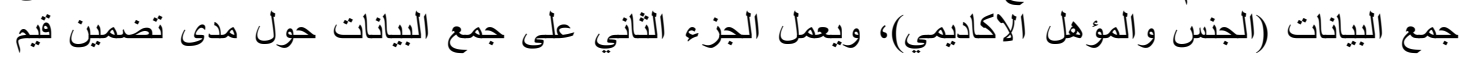
المواطنة في المجال السياسي، وتم تصميم الجزء الثياء الثاني بناء على دراسة كلٍ من: بلقاسم (2016)، العسالي 


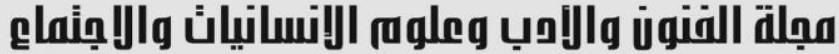

Journal of Arts, Literature, Humanities and Social Sciences

www.jalhss.com

وسويدان (2017)، الزبون واخرون (2018)، ويعمل الجزء الثالث على جمع البيانات حول مدى تضمين قيم الثيم

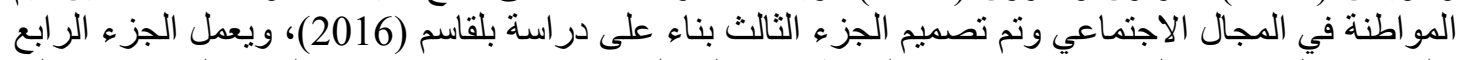

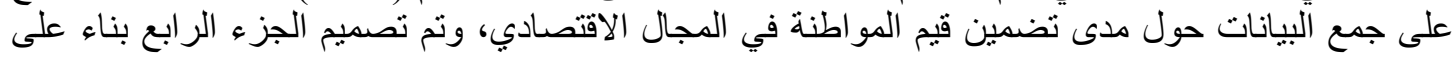

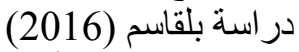

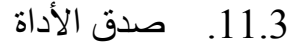

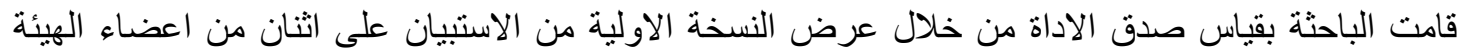

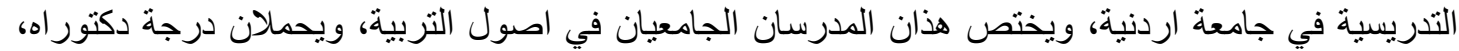

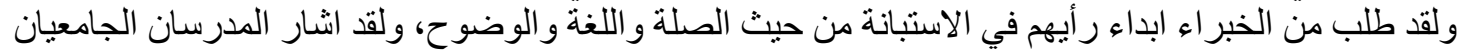

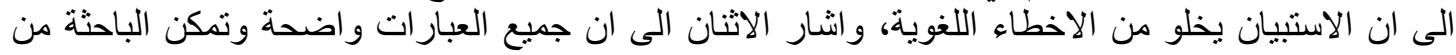

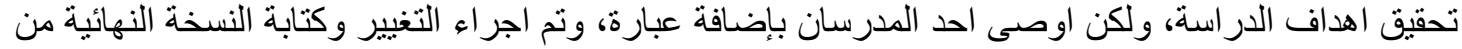

الاستبيان

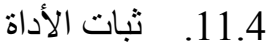

قامت الباحثة بقياس ثبات الاداة من خلال احتساب قيم معامل كرونباخ الفا لمجالات الدر اسة، وتم ادر اجها ادناه:

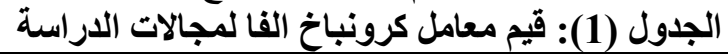

\begin{tabular}{|c|c|c|}
\hline قيمة معامل كرونباخ الفا & 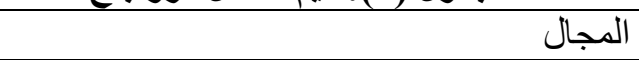 & 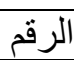 \\
\hline 0.78 & مدى تضمين قيم المواطنة في المجال السياسي & .1 \\
\hline 0.82 & مدى تضمين قيم المواطنة في المجال الاجتماعي & .2 \\
\hline 0.85 & مدى تضمين قيم المواطنة في المجال الاقتصادي & .3 \\
\hline 0.81 & الإجمالي & \\
\hline
\end{tabular}

ان جميع القيم تشير الى ان الادة تتمتع بدرجة عالية من الثبات، وتعمل على توفير نتائج دقيقة، وذللك لأن القيم

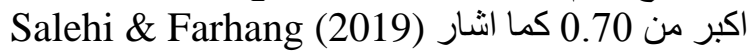

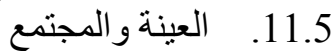

تكون مجتمع الدر اسة بجميع معلمي معلمي التربية الوطنية و المدنبة للصف التاسع في الاردن، ولقد قامت التئ الباحثة

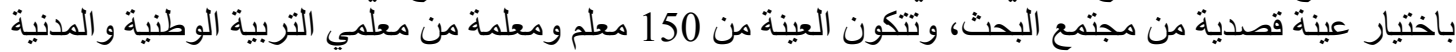

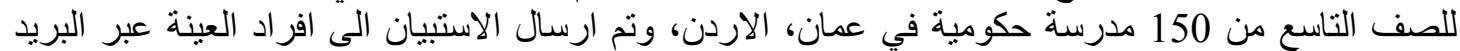

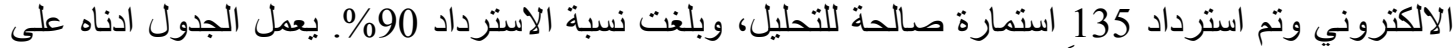

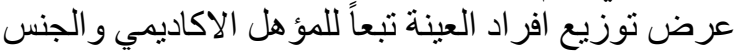

\begin{tabular}{|c|c|c|c|}
\hline النسبة & التكر ار ات & الفئة & المتغير \\
\hline 45.92 & 62 & ذكور & \multirow[t]{2}{*}{ الجنس } \\
\hline 54.07 & 73 & اناث & \\
\hline 84.44 & 114 & بكالوريوس & \multirow[t]{4}{*}{ المؤهل الاكاديمي } \\
\hline 6.66 & 9 & دبلوم عالي & \\
\hline 8.88 & 12 & ماجستير & \\
\hline 0 & 0 & دكتور اه & \\
\hline
\end{tabular}

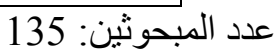

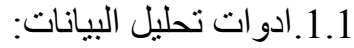
لقد نم استخدام ادوات الاحصاء الوصفي، وتم استخدام برنامج SPSS لتحليل البيانات، ولقد قامت الباحثة

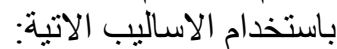
-تم احتساب المتوسطات والاتية: الانحر افات المعيارية لتحليل اتجاهات المبحوثين

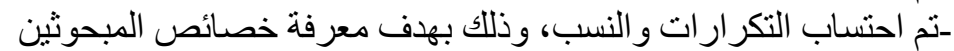

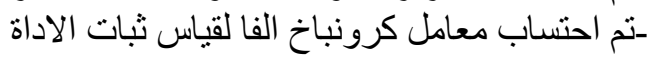

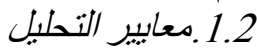




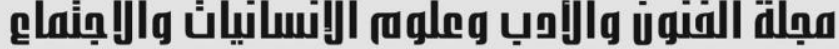

Journal of Arts, Literature, Humanities and Social Sciences www.jalhss.com

من اجل تصنيف المتوسطات، فلقد تم اتباع المعايير المدرجة ادناه في الجدول (2):

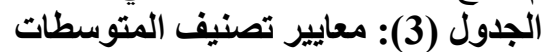

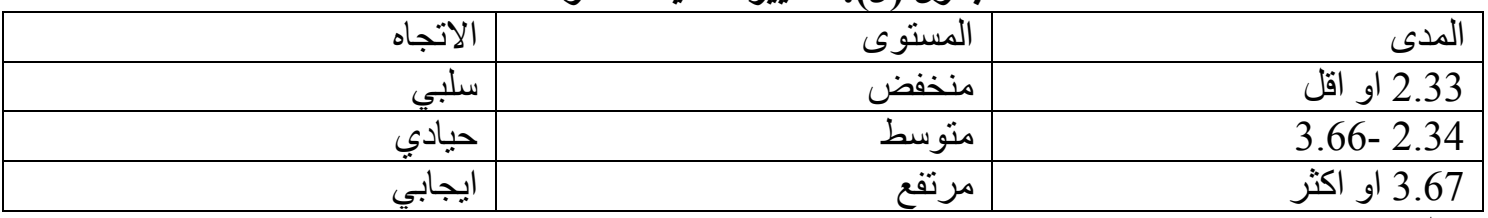

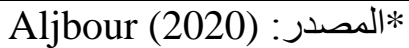
تم اعتماد مقياس ليكرت الخماسي المكون من خمس فئات. يعمل الجدول ادناه على عرض هذئ هذه الفئات:

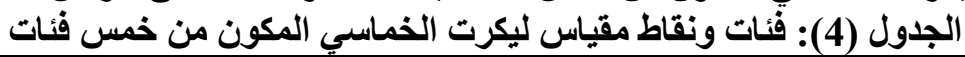

\begin{tabular}{|c|c|}
\hline النقاط & الفئة \\
\hline 5 & او افق بشدة \\
\hline 4 & أو افق \\
\hline 3 & حيادي \\
\hline 2 & لا لأوافق \\
\hline 1 & لا لا اوق بشدة \\
\hline
\end{tabular}

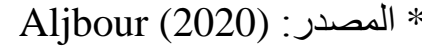
12. النتائج و المناقثنة المتعلقة بسؤ ال الدر اسة

سؤال الدر اسة: ما مدى تضمين قيم المو اطنة في منهاج التربية الوطنية والمدنية للصف التاسع في الأردن من

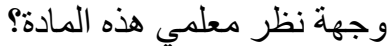
للإجابة على هذا السؤ ال، تم القيام باحتساب المتوسطات والانحر افات المعيارية الخاصة بكل مجال من مجالات الجدول (5): المتوسطات والانحرافات المعيارية الخاصة بكل مجال من مجالات الاراسة

\begin{tabular}{|c|c|c|c|c|c|}
\hline 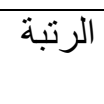 & المستوى & 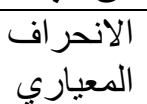 & الحسابي & 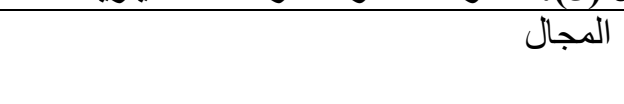 & 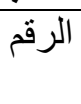 \\
\hline 2 & مرتفع & 0.35 & 4.11 & مدى تضمين قيم المو اطنة في المجال السياسي & .4 \\
\hline 1 & مرتفع & 0.33 & 4.24 & مدى تضماعين قيم المواطنة في المجال & .5 \\
\hline 3 & مرتفع & 0.32 & 4.07 & مدى تضادين قيمين المواطنة في المجال & .6 \\
\hline & مرتفع & 0.33 & 4.14 & 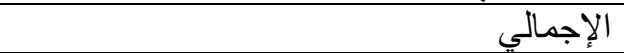 & \\
\hline
\end{tabular}

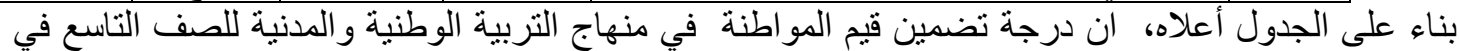

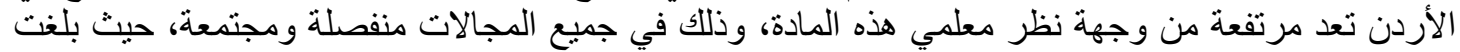

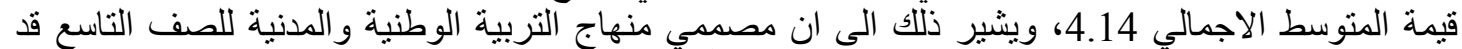

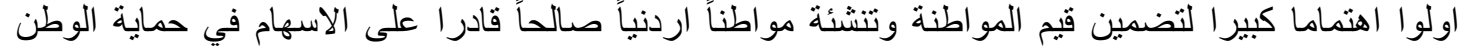

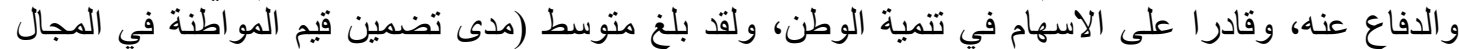

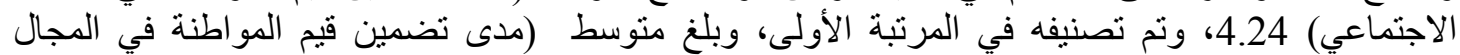

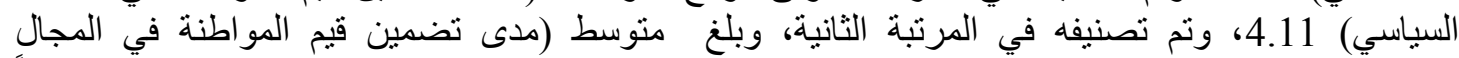

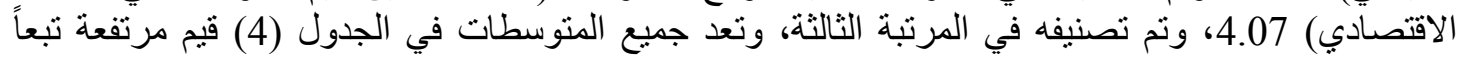




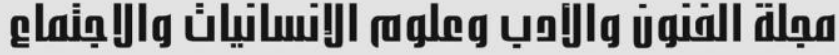

Journal of Arts, Literature, Humanities and Social Sciences

www.jalhss.com

الجدول (6): مدى تضمين قيم المواطنة في منهاج التربية الوطنية والمدنية للصف التاسع في الأردن في

أو لا: مدى تضمين قيم المو اطنة في المجال السياسي المجال السياسي التربي الوطي

\begin{tabular}{|c|c|c|c|c|c|}
\hline الاتجاه & المستوى & 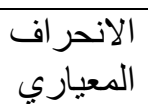 & 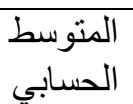 & 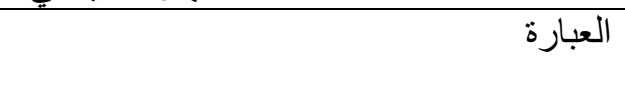 & 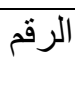 \\
\hline & & & & التاسه في الأردن في التربية الوطنية والمدنية للصف & \\
\hline إيجابي & مرتفع & 0.54 & 4.76 & تعزيز الانتماء الوطني & .1 \\
\hline إيجابي & 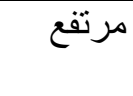 & 0.21 & 4.48 & في الثجيع الطلبة على احترام الأنظمة و القوانين & .2 \\
\hline إيجابي & مرتفع & 0.17 & 4.63 & تعزيز الارتباط بالوطن وصقل الهوية الوطنية & .3 \\
\hline إيجابي & مرتفع & 0.32 & 4.57 & النشجيع على أداء الواجبات الوطنية & .4 \\
\hline حيادي & متوسط & 0.40 & 3.60 & نشر السلام العالمي ما بين الشعوب & .5 \\
\hline إيجابي & مرتفع & 0.48 & 4.75 & تعزيز مبدأ المساو اة في الحقوق والواجبات & .6 \\
\hline إيجابي & مرتفع & 0.61 & 4.91 & تعزيز الوعي حول وجوب طاعة الحاكم & .7 \\
\hline سلبي & منخفض & 0.17 & 2.32 & تشجيع الطلبة على الانخراط في الأنشطة & .8 \\
\hline سلبي & منخفض & 0.28 & 2.28 & نشر المعرفة حول إنجازات الحكومة & .9 \\
\hline إيجابي & مرتفع & 0.39 & 4.86 & نشر المعرفة حول الحقوق الدستورية & .10 \\
\hline إيجابي & مرتفع & 0.35 & 4.11 & الإجمالي & \\
\hline
\end{tabular}

المصدر: بلقاسم (2016)، العسالي وسويدان (2017)، الزئ الزبون واخرون (2018)

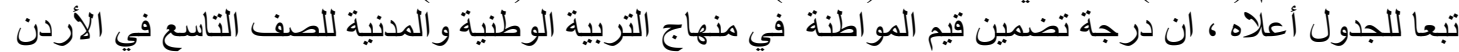

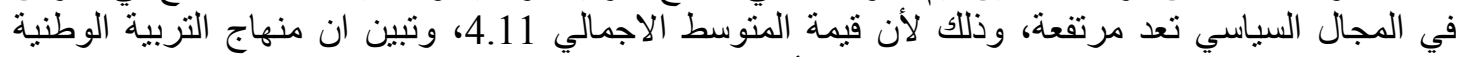

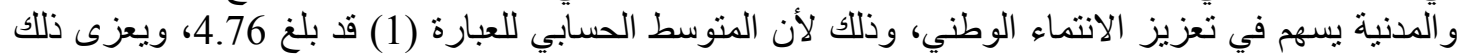

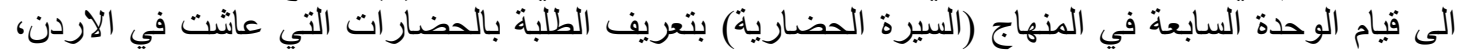

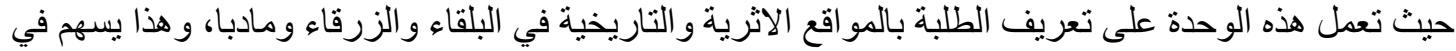

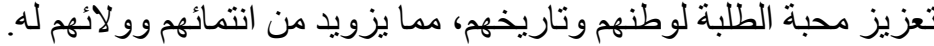

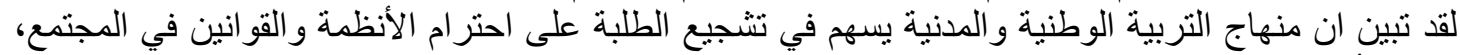

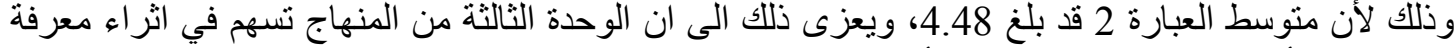

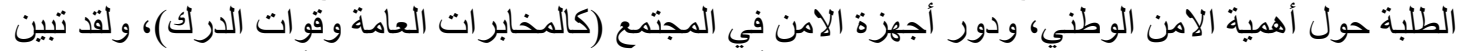

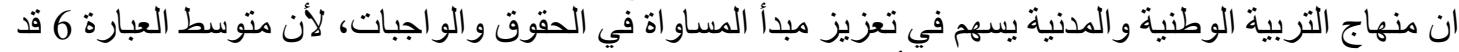

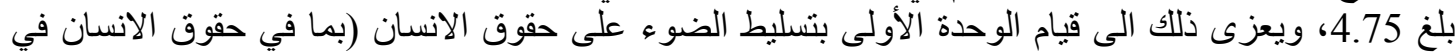

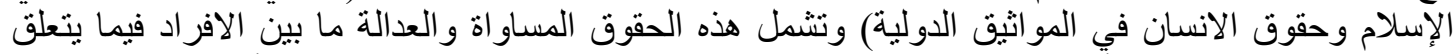

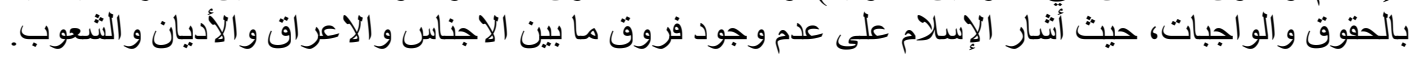

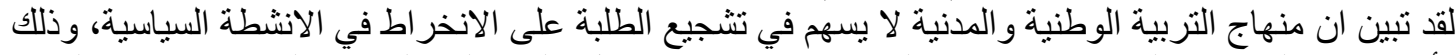

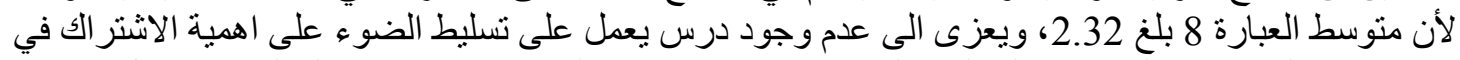

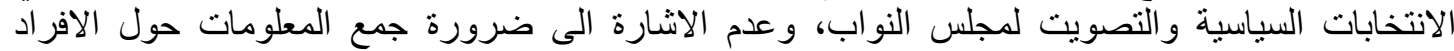

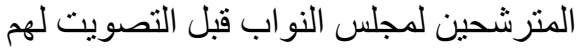




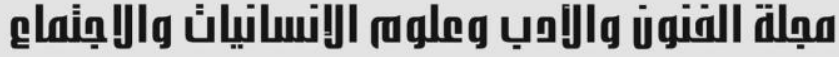

Journal of Arts, Literature, Humanities and Social Sciences www.jalhss.com

الجدول (7): مدى تضمين قيم المواطنة في منهاجِ التربية الوطنية والمدنية للصف التاسع في الأردن في

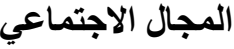

\begin{tabular}{|c|c|c|c|c|c|}
\hline الاتجاه & المستوى & 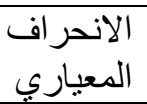 & الحسابي المتي & 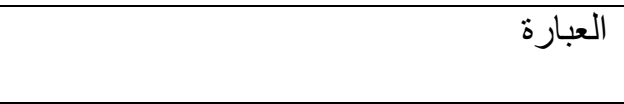 & 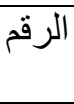 \\
\hline & & & & 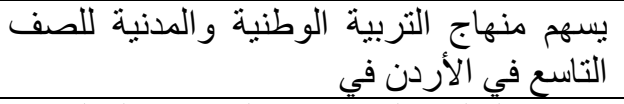 & \\
\hline ايجابي & مرتفع & 0.25 & 4.59 & تشجيع الطلبة على احتر ام العادات و التقاليد في & .1 \\
\hline ايجابي & مرتفع & 0.16 & 4.42 & تنمية اتجاهات إيجابية نحو العمل المهني & .2 \\
\hline ايجابي & 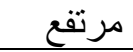 & 0.34 & 4.67 & التأكيد على ضرورة التسامح مع الاخر & .3 \\
\hline ايجابي & 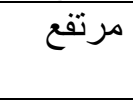 & 0.27 & 4.88 & وتقبله & .4 \\
\hline ايجابي & مرتفع & 0.64 & 4.51 & التأكيد على أهمية احتر ام مختلف الأعر اق & .5 \\
\hline ايجابي & مرتفع & 0.18 & 4.97 & تتمية الاعتز از بالتر اث الوطني & .6 \\
\hline | ايجابي & 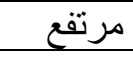 & 0.35 & 4.62 & تعزيز الاحتر ام للراي الاخر & .7 \\
\hline سلبي & منخفض & 0.57 & 2.20 & خلال الحوار الطلبة على حل الخلافات ما بينهم من & .8 \\
\hline سلبي & منخفض & 0.38 & 2.14 & و نشر الوعيب حول ضرورة محاربة الاشاعات & .9 \\
\hline ايجابي & مرتفع & 0.42 & 4.83 & الخيرية والتطو عية على المساهمة في الاعمال & .10 \\
\hline ايجابي & مرتفع & 0.14 & 4.90 & و الاثرية الوعي حول أهمية زيارتهاية المواقع التاريخية & .11 \\
\hline ايجابي & مرتفع & 0.33 & 4.24 & الإجمالي & \\
\hline
\end{tabular}

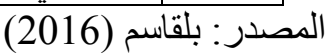

تبعا للجدول أعلاه، ان درجة تضمين قيم المواطنة في منهاج التربية الوطنية و المدنية للصف التاسع في الأردن

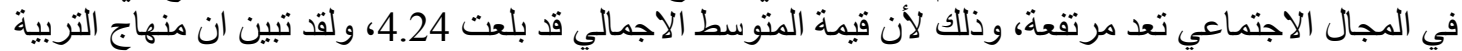

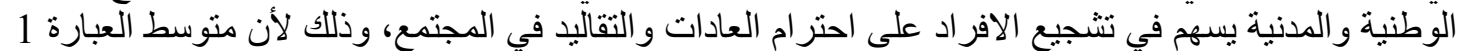

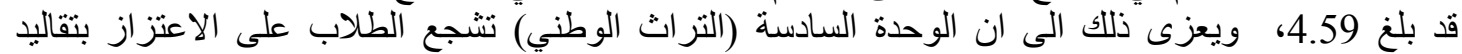

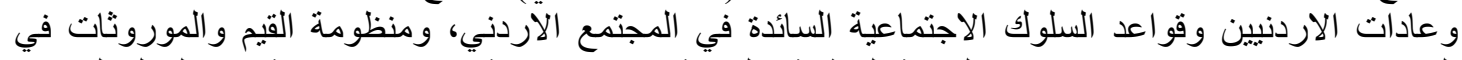

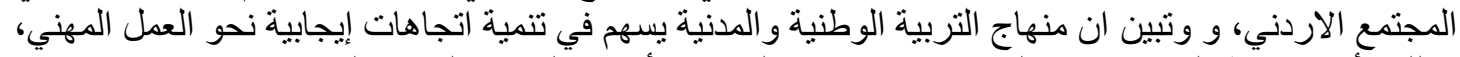

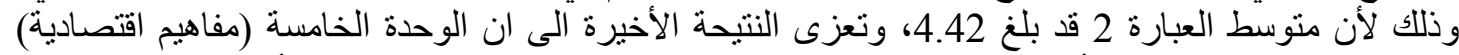

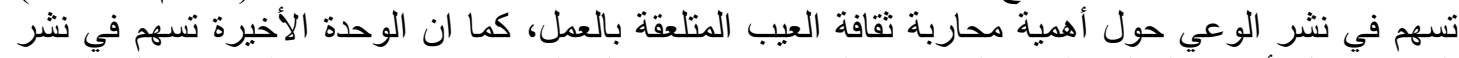
الوعي حول أهمية العمل بالنسبة للافراد والمجتمع، مما يجعل الفرد الاردن مقبلا على الاعمال المهنية الإنية و الأكاديمية

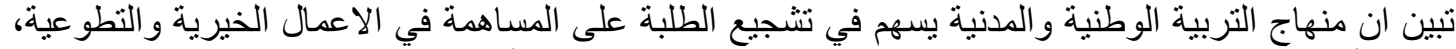

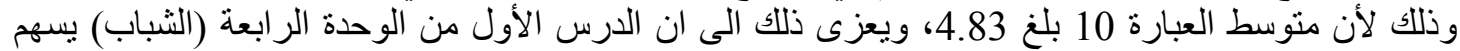

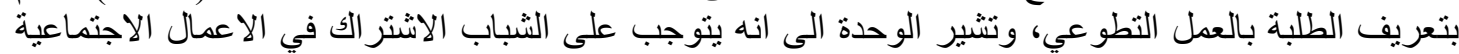

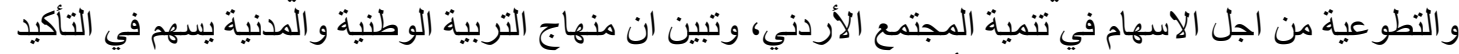

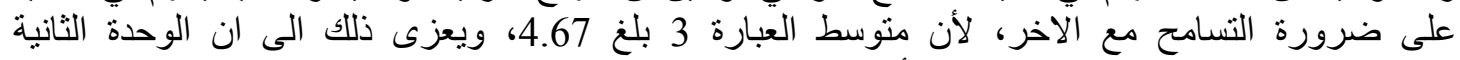
(الديمقر اطية) نتجع الطلبة على التسامح كأساسٍ لنشر الديمقر اطية في المجنمع الاردني. 


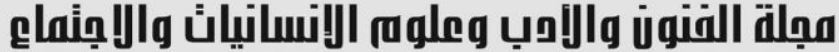

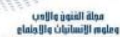

Journal of Arts, Literature, Humanities and Social Sciences

www.jalhss.com

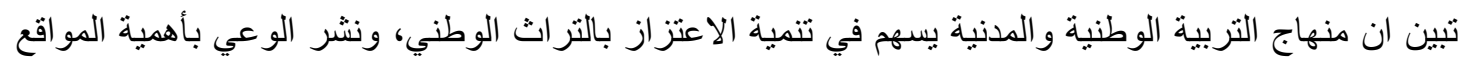

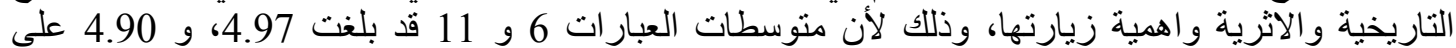

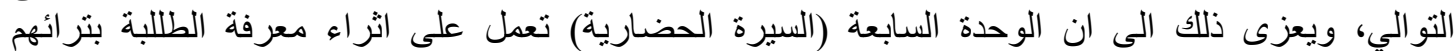

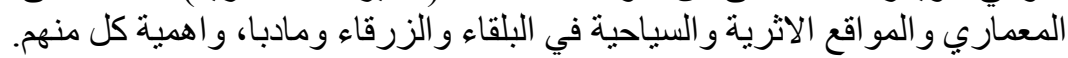

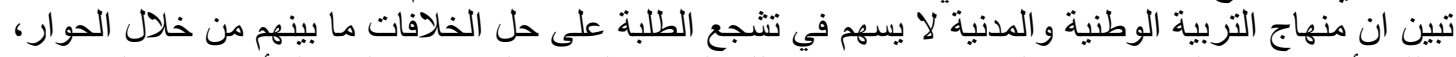

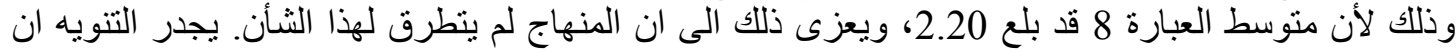

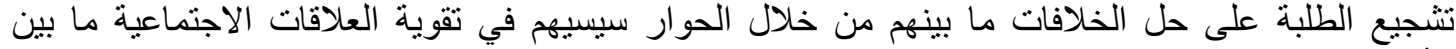

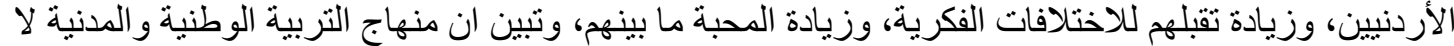

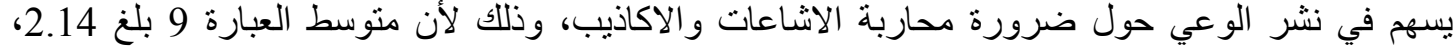

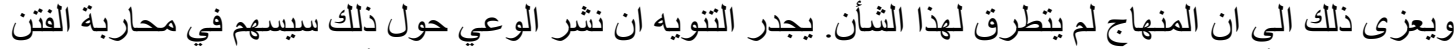

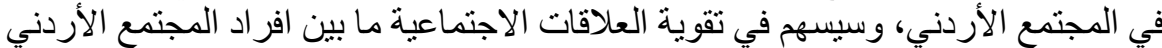

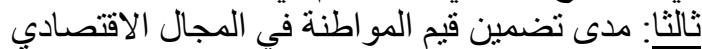

الجدول (8): مدى تضمين قيم المواطنة في منهاج التربية الوطنية والمدنية للصف التاسي في الأردن في

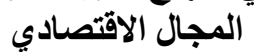

\begin{tabular}{|c|c|c|c|c|c|}
\hline الاتجاه & 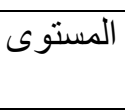 & المعياري الانحر اف & الحسابي & 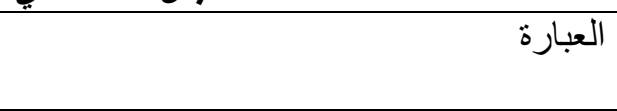 & 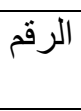 \\
\hline & & & & التاسع في الأردن في التربية الوطنية و المدنية للصف & \\
\hline سلبي & منخفض & 0.14 & 2.05 & 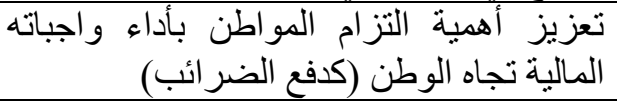 & .1 \\
\hline إيجابي & مرتفع & 0.23 & 4.91 & تشجيع الطلبة على العمل بصدق و امانة & .2 \\
\hline إيجابي & 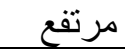 & 0.48 & 4.76 & تشجيع الطلبة على حماية البيئة & .3 \\
\hline سلبي & منخفض & 0.37 & 1.90 & تشجيع الطلبة على الاستفادة من وقت الفر اغ & .4 \\
\hline إيجابي & 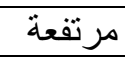 & 0.15 & 4.55 & تشجيع الطلبة على حماية الممتلكات العامة & .5 \\
\hline إيجابي & مرتفع & 0.66 & 4.34 & نشر الوعي حول اهمية زيادة الإنتاجية & .6 \\
\hline إيجابي & مرتفع & 0.49 & 4.72 & تشجيع الطلبة على دعم الاقتصـاد الوطني & .7 \\
\hline إيجابي & 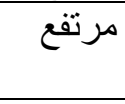 & 0.25 & 4.85 & تتبلقيع الطلبة على محاربة ثقافة العيب فيما & .8 \\
\hline إيجابي & مرتفع & 0.13 & 4.60 & تشجيع الطلبة على الامتناع عن هدر الموارد & .9 \\
\hline إيجابي & مرتفع & 0.32 & 4.07 & 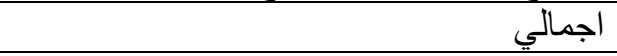 & \\
\hline
\end{tabular}

$$
\text { المصدر: بلقاسم (2016) الميال }
$$

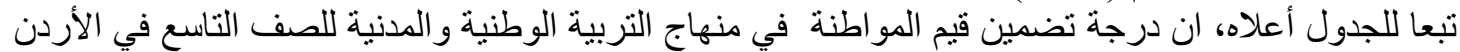

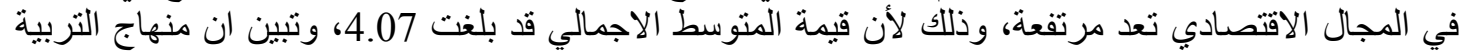

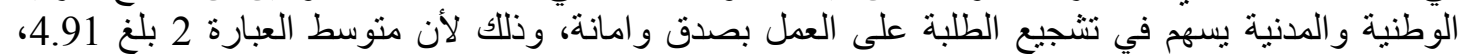

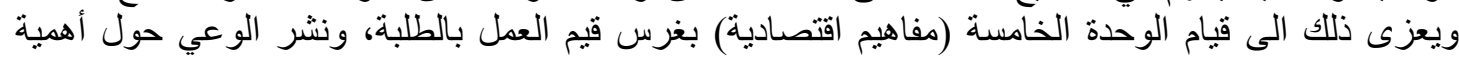

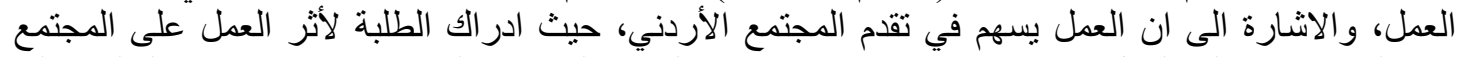

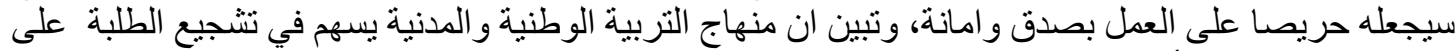

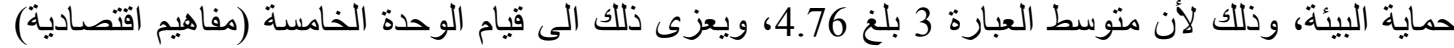

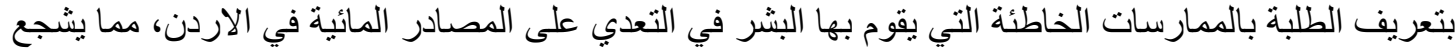

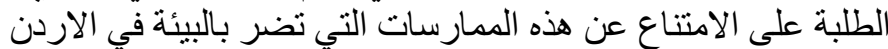

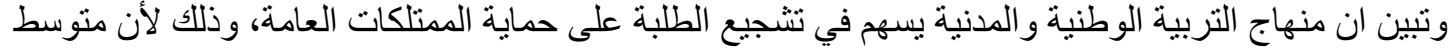

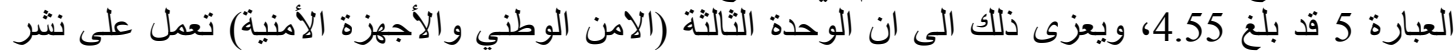

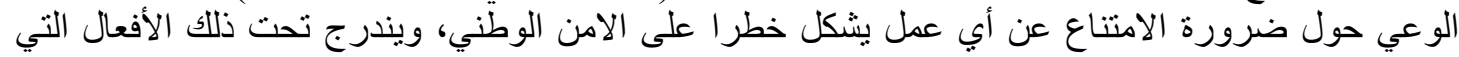

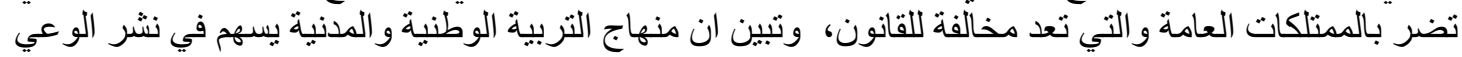




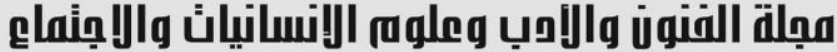

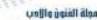

Journal of Arts, Literature, Humanities and Social Sciences

www.jalhss.com

حول أهمية زيادة الإنتاجية ودعم الاقتصادي الوطني، وذللك لأن متوسطات العبارات 6و 7 بلغ بلغ 4.34 و و

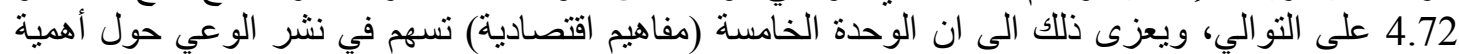

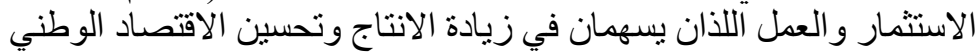

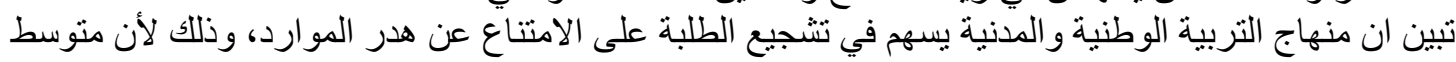

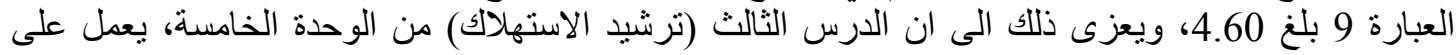

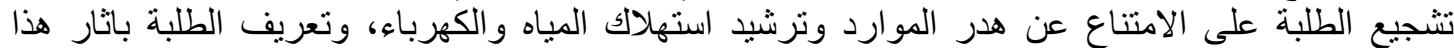

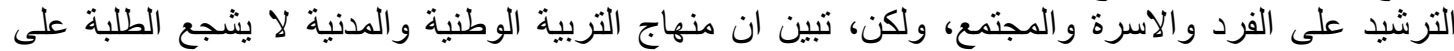

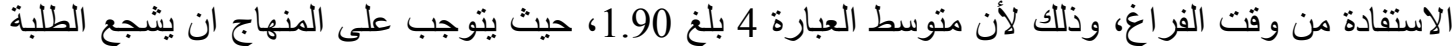

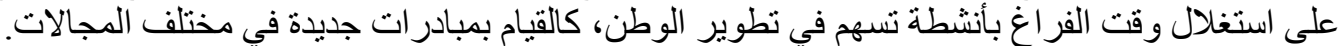

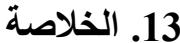

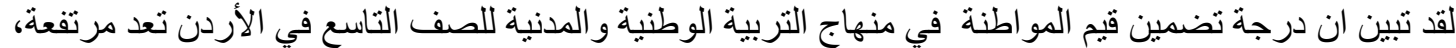

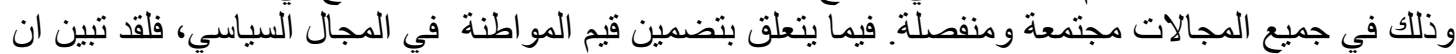

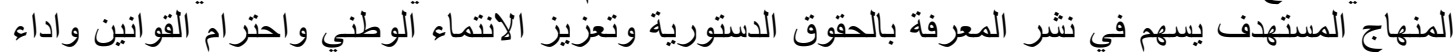

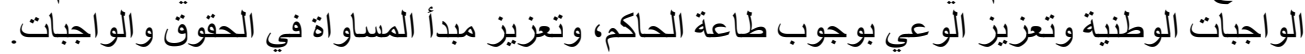

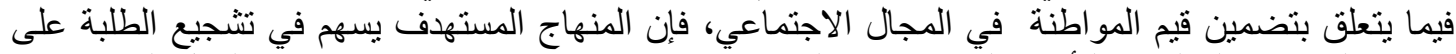

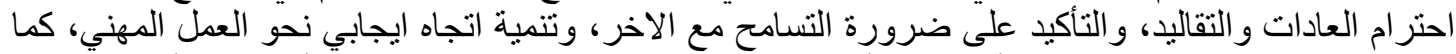

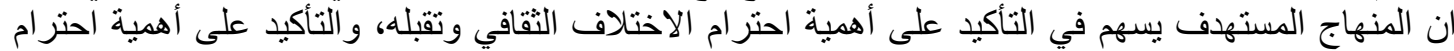

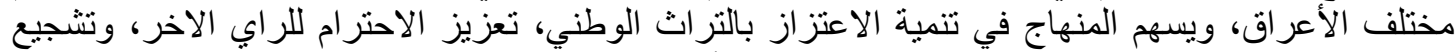

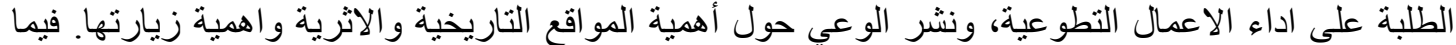

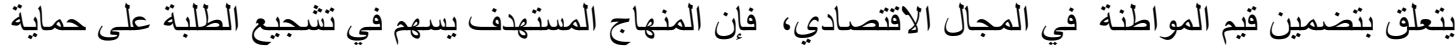

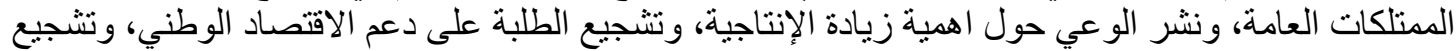

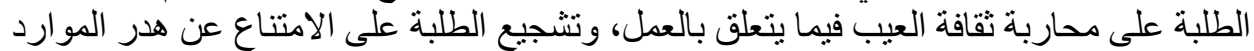

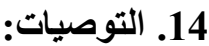

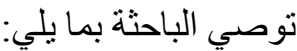

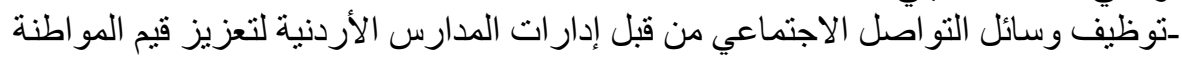

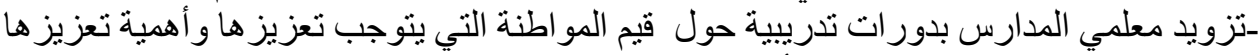

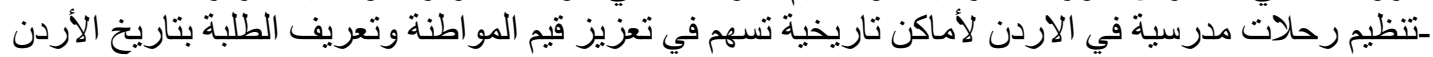

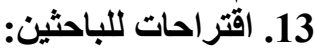
توصي الباحثة بما يلي: البين:

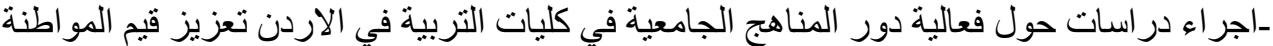

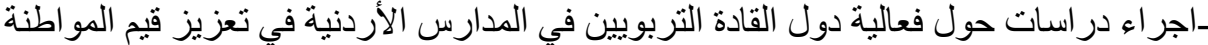

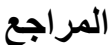

1. احمد، طلال (2016). دور التربية الإسلامية في معالجة أثر المتغيرات الثقافية على مفهوم المواطنة لدى

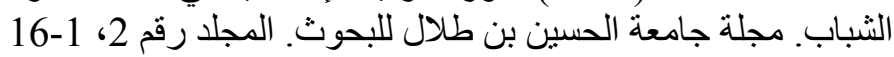

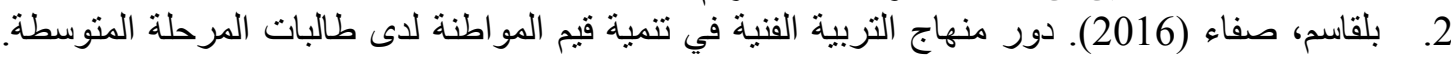

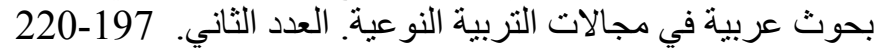
3. بهاء الدين ، حسين كامل (2000). الوطنية في عالم بلا هوية ـ تحديات العولمة ،القاهرة. مصر. ـ دار

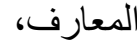

4. الجعبري، طارق (2018). و واقع المنهاج الفلسطيني في تعزيز الصورة الذهنية للوطن : دراسة استقصائية تحليلية في منهاج التربية الوطنية في المرحلة الأساسية. المركز الديمقراطي العربي الرئيسية الثرق الثرة الأوسط. https://democraticac.de/?p=56940 5. أبو حشيش، بسام محمد(2010). دور كليات التربية في تتمية قيم المو اطنى لاى الطلبة المعلمين بمحافظات غزة. مجلة جامعة الأقصى (سلسلة العلوم الإنسانية). 14(1). 


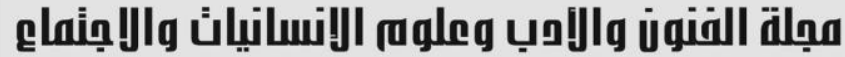

Journal of Arts, Literature, Humanities and Social Sciences

www.jalhss.com

6. الحفظي، عبد الرحمن (2005). دور التربية الوطنية في تتمية المواطنة في المجتمع السعودي. رسالة ماجستير غير منشورة. جامعة ام القرى. مكة المكرمة. السعودية الرية

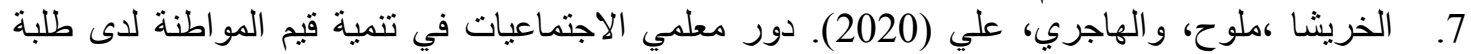

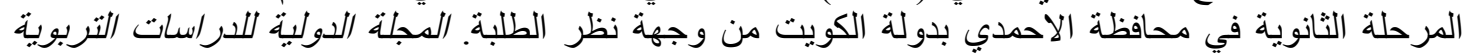
،361 $-346$

.(2) 8 والنفسية.

DOI: https://doi.org/DOI:10.31559/EPS2020.8.2.8

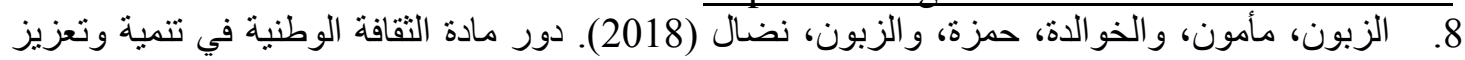

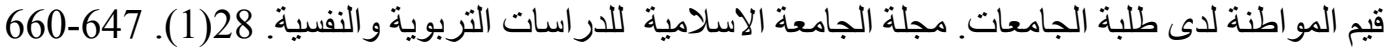

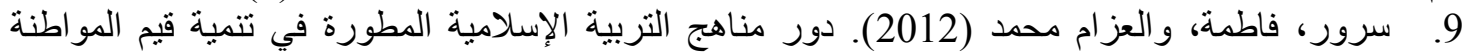

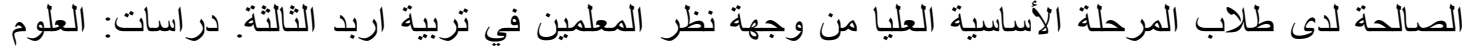

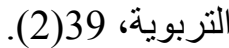
10. السلمي، أحلام (2019) الكية مفهوم القيم وأهميتها في العملية التربوية وتطبيقاتها السلوكية من منظور إسالمي. المجلة العربية للعلوم ونشر الابحاث. 2(2018).

Doi: 10.26389/AJSRP.A160918.11

12. شحاته، حسن (2008). تصميم المناهج و قيم التقام في العالم العربي. الطبعة الاولى. الدار المصرية اللبنانية.

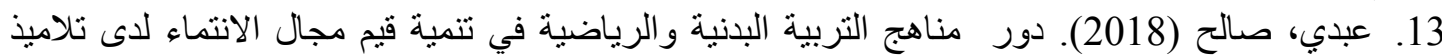

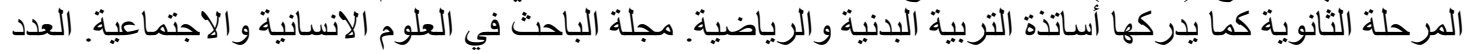
20-1،35

14. عامر، طارق طارق عبد الرؤوف (2011). المواطنة والتربية الوطنية " اتجاهات عالمية وعربية القاهرة ، ،

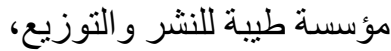

15. العسالي، علياء، وسويدان، رجاء (2018). دور الجامعات الفلسطينية في تنمية قيم المواطنة لدى الطلبة

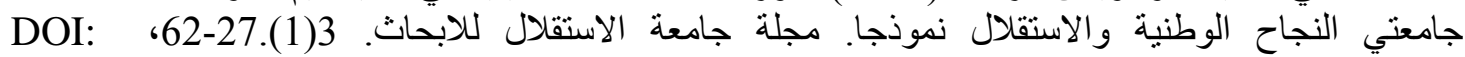
10.36554/1796-003-001-002

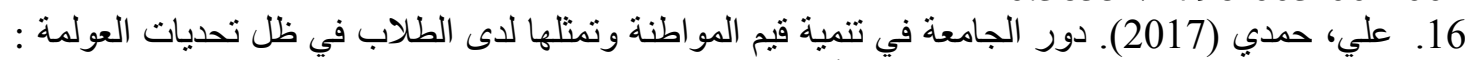

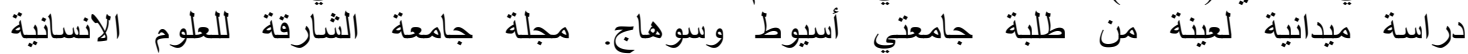

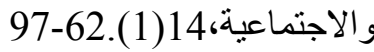

17. فرج، الهام (2001). المناهج الدراسية والوالوعي الاجتماعي و السياس ي للمر أة في مصر ."التعليم ومستقبل

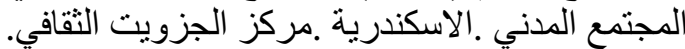

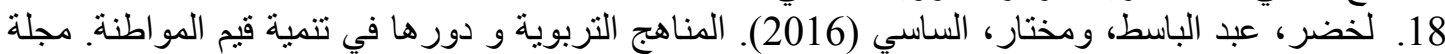

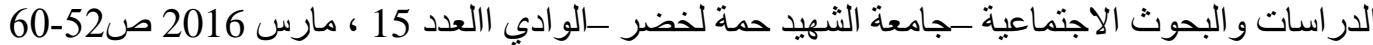

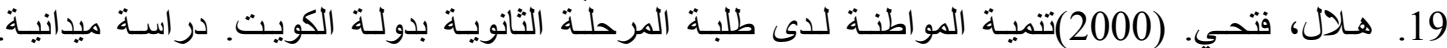

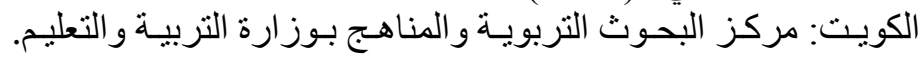

\section{References}

1. Al- Gassem, T. (2020). The Role of Jordanian Universities in Promoting Citizenship Values among Students. Journal of Education and Practice. 11(33). DOI: 10.7176/JEP/11-33-08

2. Aljbour, H. (2020). The extent of practicing ethical leadership by public secondary school principals in Amman. Journal of Education and Practice. 11(15). 57-63, DOI: 10.7176/JEP/11-15-07 


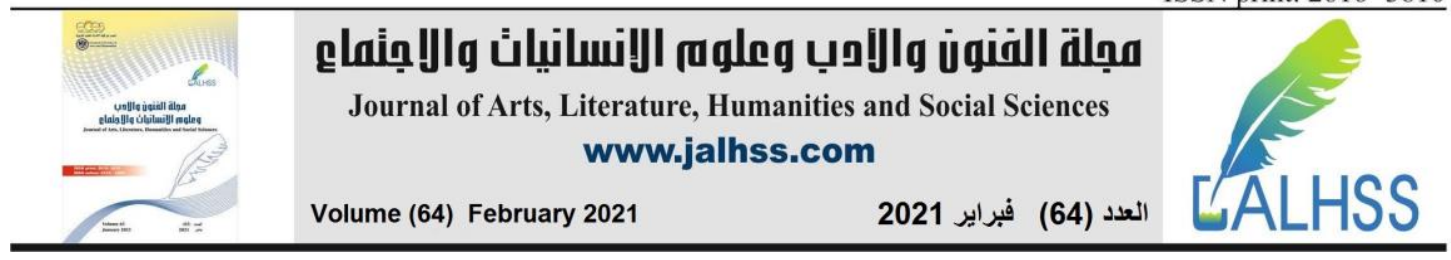

3. Altintaş and Karaaslan (2019). Study on Effective Citizenship Education and Its Dimensions, Universal Journal of Educational Research, 7(7): 1567-1579, DOI: 10.13189/ujer.2019.070711

4. Dustin, W. (2000). Toward an Ethic of Citizenship: Creating a Culture of Democracy for the 21St Century. USA. iUniverse.

5. Geboers, E. \& Geijsel, F. \& Admiraal, W. \& Dam, G.. (2013). Review of the effects of citizenship education. Educational Research Review. 9. 158-173. Doi: 10.1016/j.edurev.2012.02.001.

6. Gwen, W. (2008) "The Meaning of Citizenship to Young Adults in the Postcommunist Czech Republic". Unpublished PhD. Thesis. University of Minnesota. Minnesota State. USA.

7. Haynes, J. and Passy, R. (2013). Education, extremism and terrorism: what should be taught in citizenship education and why. Journal of Education and Teaching. 39(4). 464-466, https://doi.org/10.1080/02607476.2013.825458

8. Hoskins, B., Saisana, M. \& Villalba, C. (2015). Civic Competence of Youth in Europe: Measuring Cross National Variation through the Creation of a Composite Indicator. Social Indicators Research, 123, 431-457 (2015). https://doi.org/10.1007/s11205-014-0746-Z

9. Jacquie Turnbull (2002) Values in educating for citizenship: sources, influences and assessment. Pedagogy, Culture \& Society, 10:1, 123-134, DOI: $10.1080 / 14681360200200135$

10. Koutselini, M. (2008). "Citizenship Education in Context: Student Teacher Perceptions of Citizenship in Cyprus",

$\begin{array}{lll}\text { 11. Intercultural 163-175, } & \text { Education. }\end{array}$ https://doi.org/10.1080/14675980801889690

12. Martin, T \& Yap, P. (2011). "Civic. Disparities: Exploring Student's Perceptions of citizenship within sing a pore's Academic Tracks". Theory and research in Social Education. 39 (2): 203-237, https://doi.org/10.1080/00933104.2011.10473453.

13. Saleh, R.; and Al-Zboon, M. (2020). The Role of the Jordanian High Schools in Deepening Good Citizenship among their Students. Journal of Education and Practice. 11(6), 37-45, DOI: 10.7176/JEP/11-6-05

14. Salehi, M., \& Farhang, A. (2019). On the adequacy of the experimental approach to construct validation: the case of advertising literacy. Heliyon, 5(5), https://doi.org/10.1016/j.heliyon.2019.e01686

15. Westheimer, J.; and Kahne, J. (2004). What Kind of Citizen? The Politics of Educating for Democracy, American Educational Research Journal. 41(2), 237-269, https://doi.org/10.3102/00028312041002237 